\title{
On the Modelling of Integrated AHP and CoCoSo Approach for Robust Design of Multi-objective Optimization of thinning Parameters for Maximum thinning Rate and Determine Optimum Locations for Directionally-rolled Deep-drawn Cups using Scaling Laws
}

Sundar Sivam ( $\sim$ legendsundar2k6@gmail.com )

SRM Institute of Science and Technology

R. Rajendran

SRM Institute of Science and Technology

Original Article

Keywords: MCDM, rolled, Deep-Drawing, AHP, CoCoSo, ANOVA, thinning-rate

Posted Date: November 17th, 2020

DOI: https://doi.org/10.21203/rs.3.rs-106434/v1

License: (c) (1) This work is licensed under a Creative Commons Attribution 4.0 International License.

Read Full License 
On the modelling of integrated AHP and CoCoSo approach for robust design of multiobjective optimization of thinning parameters for maximum thinning rate and determine optimum locations for directionally-rolled deep-drawn cups using scaling laws

S.P. Sundar Singh Sivam ${ }^{1 *}$, R. Rajendran ${ }^{2}$

${ }^{1}$ Department of Mechanical Engineering, College of engineering and Technology, SRM Institute of Science and Technology, Kattankulathur- 603203, Tamil Nadu, India

${ }^{2}$ Department of Automobile Engineering, Centre for Automotive Materials, College of engineering and Technology, SRM Institute of Science and Technology, Kattankulathur- 603203, Tamil Nadu, India

"Corresponding Author: Tel (+91) 8610502557; Email ID: legendsundar2k6@gmail.com

\section{Abstract:}

Objectives - Since parts and components are manufactured of different sizes and geometries, the fabrication of such parts of various size could be predicted the process parameters that affect the performance based on scaling laws and could be verified through experimentation. The purpose of this study is to determine optimum thinning process parameter settings of directionally rolled deep drawn copper cups at specified critical zones or regions for making miniaturized components and parts that results in better-quality products. Design/ Methodology/ Methodology - This study presents an integrated Analytic Hierarchy Process (AHP) with Combined Compromise Solution (CoCoSo) decision making algorithm to arrive a consolidation strategy with robust Taughi's design of experiments, primarily to increase the accuracy of prediction of process parameters that affects the thinning rate of the deep-drawn cups. The weights of the alternatives is arrived with AHP and followed by CoCoSo method to determine the general multiplication factor to rank the alternatives by decision-making process. In this work, four control factors namely, number of stages of forming, clearance, punch nose radius, and coefficient of friction between $\mathrm{x}$, were considered, with each at three levels, for determining the maximum thinning-rate at three different zones or locations namely, Cup-base, cup-nose-radius, and wall. Conclusions-This study described the real situation when forming performance on multi-stage deep-drawing with Uni-directional and bi-directional processed samples. The comparisons, such as sensitivity analysis approaches, methods developed to validate the proposed model.The virtual response were compared with the results of experiments on current multi stage deep drawing processes, good agreement being found. Originality/ Value - In this work a combined model using AHP and CoCoSo was attempted to improve the robustness of the products used for manufacturing miniaturized devices, which were not widely explored, and such integrated Multi-criteria decision-making (MCDM) methods was first proposed for engineering applications in the manufacturing field.

Keywords: $M C D M$, rolled, Deep-Drawing, AHP, CoCoSo, ANOVA, thinning-rate

\section{Introduction}

With increasing demand for high-quality miniaturized products, such as portable consumer electronics and other meso- and microscaled devices, and components with characterized and localized microscaled features, such as microchannel bipolar plate (BPP) in fuel cells wherein micro and multi-stage manufacturing technologies are critically needed. Microforming, as one of the promising micromanufacturing technologies, has achieved remarkable development and has been used in some relevant industries in the past few decades. The meso and microforming processes including mesoand microscaled stamping, embossing, punching, forming, coining, extrusion, and progressive and compound bulk forming have been explored and developed [1-4]. Among these approaches, meso- and multi stage forming has been well studied for their promising potential applications in mass production of micro metallic products in different industrial clusters for its low production cost, high efficiency, limited space occupation, and low energy consumption. Due to these advantages, meso- and multistage forming process has been extensively used to produce miniaturized parts and components in different area as such as microelectromechanical systems, renewable energy, electronics, biomedicines, aerospace, micro reactors, etc.Until now numerous research projects and investigations have been conducted on meso- and micro and multi stage forming, and a considerable improvement in process capability has been done in recent years in terms of formation of new materials, development of new products, and viability of forming devices and processes. Therefore, extra efforts have been provided to explore the fully automatic meso- and multi stage forming i.e. multi stage deep drawing for the production of miniaturized products. However, there is a big gap between research conducted in laboratories and actual production. Some critical issues should be successfully addressed before the wide application of unique meso- and microforming processes. The first issue is the design of microproducts. Design of microproducts for meso- and micro and multi stage deep drawing needs to consider the production issues, viz., design for manufacturing, such that the design can be efficiently fabricated and the capability of the process can be fully employed and considered in upfront design stage [5].

The mechanism of multi-stage drawing is very complex, the blank follow-up process has gone through one or more steps deforming, and material has certain changes in geometrical mechanical properties and thickness uniformity, which bring some difficulty on the study of multi-stage drawing. Traditional research through physical simulation or experiments can only get qualitative rather than quantitative analysis for the multi-stage drawing process. Recently, with the development of computer technology and the finite element method, numerical simulation technology in sheet metal forming has got a great deal progress. Computer simulation can 
reflect interaction between the mold and sheet metal, as well as the whole deformation process, which has played an increasingly important role on promoting the rapid production and intelligent design [6].

Design environments are particularly sensitive to conflicts [7]. If the risks are too high, it is important to identify the issue, precisely the contradictory criteria, so modern decision makers (scientists and experienced users) have to explicitly assess various criteria rather than make decisions based only on intuition and experience special. The good design of complex issues and the explicit handling of the different rules will lead to better informed and better decisions. The concept of sustainable development, increasingly represented in all areas of activity, is one of the accredited researchers in the construction sector [8]. In the practical problem-solving process, different groups of decision-makers participate and each group has different criteria and positions to be solved by mutual understanding and conciliation. Problems are often characterized by a number of inadequate and contradictory criteria (competition), but the solution may not meet all requirements. Stakeholders need commitment. Complex problems solved in the last decades imply that the decision maker tries to compromise other objectives: financial, ethical or otherwise. Strong options are those solutions that represent the outcome of the process or which occurs after applying an algorithm [9]. Thus, the worst-case scenario is commitment according to the preferences of the decision-makers. The multi-criteria optimization is a process of determining the best feasible solution according to the established criteria (representing different effects). Algorithmic thinking and model building in MCDM provide a contemporary approach for explaining certain kinds of human behavior and decision-making [10]. MCDM is one of the most attractive fields of interdisciplinary research in management science andoperations research [11]. The first references to multiple-criteria methods were already mentioned, respectively. The first decision-making axioms were formed by Ramsey (1931). Later, von Neumann and Morgenstern (1944) introduced theory of games and economic behavior. MCDM and MCDA (multi-criteria decision analysis) are well-known acronyms for multiple-criteria decision-making and multiple-criteria decision analysis [12]. [13]. Focused on the applications of MCDM and started popularizing the acronym "MCDM". MCDM methods include two classes of methods, namely, continuous and discrete methods, based on the nature of the considered alternatives. Continuous methods, or multiobjective decision-making methods, aim to identify an optimal quantity, which can vary infinitely in a decision problem. Discrete MCDM methods, or multi-attribute decision-making (MADM) methods, can be defined as decision support techniques that have a finite number of alternatives, a set of objectives, criteria by which the options judged, and a method of ranking choices, based on how well they satisfy the goals and measures.

Literature review did not show much studies on the integrated AHP with combined compromise solution. Many research findings have shown that the applications of the SAW, MOORA, COPRAS, TOPSIS and VIKOR algorithms are very promising and were widely used in the decision-making process for industrial engineering and it is applications. The purpose of this work is to determine optimum thinning process parameter settings of directionally rolled deep drawn copper cups at specified critical zones or regions for making miniaturized components and parts that results in better-quality products. The methodology adopts an integrated AHP with CoCoSo decision making algorithm to arrive a consolidation strategy with robust Taughi's design of experiments, primarily to increase the accuracy of prediction of process parameters that affects the thinning rate of the deep-drawn cups. The weights of the alternatives is arrived with AHP and followed by CoCoSo method to determine the general multiplication factor to rank the alternatives by decision-making process. In this work, four control factors namely, number of stages of forming, clearance, punch nose radius, and coefficient of friction between $\mathrm{x}$, were considered, with each at three levels, for determining the maximum thinning-rate at three different zones or locations namely, Cup-base, cup-nose-radius, and wall. Analysis of variance (ANOVA) was used to determine significance of process parameters on the responses.

\subsection{Materials and Methods}

\subsection{Materials}

Electrolytic Tough Pitch (ETP) Copper $(\mathrm{Cu})$ alloy used for structural and sensitive electronic applications was chosen for the present study and samples were cut into $300 \mathrm{~mm} \times 150 \mathrm{~mm} \times 6 \mathrm{~mm}$ strips, which were then rolled either uni-directionally (along 300 $\mathrm{mm}$ rolling direction) or bi-directionally ( along the original $300 \mathrm{~mm}$ and $150 \mathrm{~mm}$ ). Prior to rolling the strips were processed as per industry standards, firstly, thermally treated in liquid nitrogen for 10 minutes at $-196{ }^{\circ} \mathrm{C}$, followed by annealing at $150{ }^{\circ} \mathrm{C}$ for 4 hours, and air cooled before and after for each successive rolling-pass to obtain the final thermally-treatment Sheets, as illustrated in Figure 1. A scaling factor $(\lambda)$, whose values set at $1,0.5,0.25,0.125$, and 0.0625 were used to scale down the geometrical parameters of the work piece, namely the flat strips, as well as the punch and die-set proportionally. The multi-pass reductions of the original sheet thickness were reduced to $50 \%$ of its original value in nine-incremental passes, and thus resulting in sheets of $3 \mathrm{~mm}, 1.5 \mathrm{~mm}, 0.75$ $\mathrm{mm}, 0.38 \mathrm{~mm}$, and $0.18 \mathrm{~mm}$ were obtained in both uni-directional and bi-directional directions as shown in Figure 2, and were used as blanks for making deep-drawn cups using respectively scaled die-sets. The rolling was performed using Two-high roll mill of 50 ton capacity, with rolling speed of $20 \mathrm{rpm}$, roll barrel-length $600 \mathrm{~mm}$ and roll-diameter of $150 \mathrm{~mm}$. No lubricant was not used during the rolling process. The rolled strips were tested for its mechanical response to load, formability, and anisotropy, to simulate the multistage deep-drawing process using Altair Inspire Form software. 


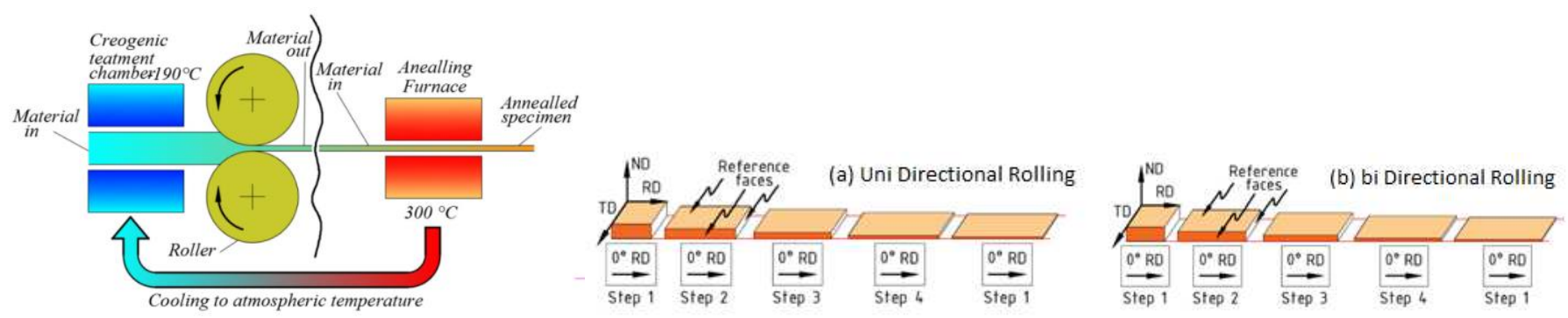

Figure 1: Schematic arrangement of rolling process Figure 2: (a, b) Process route sequence - Uni and bi directional rolling

\subsection{Method}

\subsubsection{Taguchi's robust design of the experiment}

The Taguchi's robust design method applies fractional factorial designs called Orthogonal Arrays (OA) that serve to reduce the number of experiments and still capture valuable information. For four factors each at three levels as shown in Table 1 , wherein symbol t stands for thickness of the rolled sheet or blank used. The traditional full factorial design would require 81 experiments. In the Taguchi L9 OA, however, the required experiments are only 9. To accomplish such goal, Taguchi L9 OA design (four factors with 3-level design) was used to determine and optimum process parameters at three locations or zones at formed Cup base, shoulder radius, and wall were attempted and the experiment was repeated thrice with the same conditions. L9 OA was used to determine the response parameters shown in Table 2. Each row in this table represents a trial condition with the level of factors. The design of experiment (DOE) using the Taguchi method with MCDA provides a simple, efficient, and systematic approach to determine the optimum conditions [15]. The Forming of No of Stages, Clearance, punch Radius, and Coefficient of Friction are taken as Process parameter and are individually controllable.

\section{Table 1: Process parameter Design}

\begin{tabular}{|l|c|c|c|c|}
\hline \multirow{2}{*}{ Factors or Parameters } & \multirow{2}{*}{ Unit } & \multicolumn{3}{c|}{ Levels } \\
\cline { 3 - 5 } & & $\mathbf{1}$ & $\mathbf{2}$ & $\mathbf{3}$ \\
\hline Clearance, C & $\mathrm{mm}$ & $1.5 \mathrm{t}$ & $2.0 \mathrm{t}$ & $2.5 \mathrm{t}$ \\
\hline No of Stages, N & - & 4 & 6 & 8 \\
\hline Punch Nose Radius, R & $\mathrm{mm}$ & 2 & 2.5 & 3 \\
\hline Coefficient of friction, F & - & 0.1 & 0.15 & 0.2 \\
\hline
\end{tabular}

Table 2: Standard $\mathrm{L}_{9}\left(3^{4}\right)$ experimental design

\begin{tabular}{|c|c|c|c|c|}
\hline $\begin{array}{l}\text { Simulation } \\
\text { Run }\end{array}$ & $\begin{array}{c}\text { Clearance } \\
\text { C }\end{array}$ & $\begin{array}{c}\text { No of } \\
\text { Stages } \\
\text { N }\end{array}$ & $\begin{array}{c}\text { Punch } \\
\text { Radius } \\
\text { R }\end{array}$ & $\begin{array}{c}\text { Coefficient } \\
\text { of friction } \\
\text { F }\end{array}$ \\
\hline S1 & 1 & 1 & 1 & 1 \\
\hline S2 & 1 & 2 & 2 & 2 \\
\hline S3 & 1 & 3 & 3 & 3 \\
\hline S4 & 2 & 1 & 2 & 3 \\
\hline S5 & 2 & 2 & 3 & 1 \\
\hline S6 & 2 & 3 & 1 & 2 \\
\hline S7 & 3 & 1 & 3 & 2 \\
\hline S8 & 3 & 2 & 1 & 3 \\
\hline S9 & 3 & 3 & 2 & 1 \\
\hline
\end{tabular}

\subsubsection{Multi stage deep drawing Procedure.}

The major control parameters involved in the process are: Forming of Clearance, No of Stages, Die Radius, and Coefficient of Friction which these parameters FEM simulation was made and experimental analysis for confirmation was also made. The blank holding force in the first stage of forming was applied by a ring with a suitable holding force. Whereas, the forming of the final cup was achieved in eight stages to produce the part with the Limiting Drawing Ratio (LDR) of 1.69, which was found suitable from the initial trial simulations. The process of deep drawing a cup from ETP copper was simulated using an Altair Inspire form with Quads, element size of $500 \mu \mathrm{m}$ with Adaptive meshing method and Automatic Tool positioning, Radioss Explicit solver and post processing by Altair Analysis Explorer was employed. The effect of process parameters on a defects namely wrinkles and tears, in the formation of a cup were represented in Forming limit diagram (FLD). Another important part of simulation using FEM is the selection of appropriate material model. The blank material used is ETP Copper alloy the mechanical and anisotropy properties value were determine by ASTM E8-517 method [16] and are listed in Table 5 and Table 6. The required bottom die, punch, top binder and blank were designed in Altair Inspire form 2019 using the Geometry module as shown in the below Figure 5. The multi-stage deep drawing experiments for verification are carried out using a hydraulic press of 40 ton capacity. Then the punch is driven to gradually move downward to draw the blank until the semi-finished product is formed. Take out of the semi-finished product from the die of the firststage multi stage deep drawing tooling sets and put it into the positioning plate of the second-stage micro deep drawing tooling sets and followed the same up to 8 stages as in real-time for validation. The Figure 3 shows a typical Cup with dimensional parameters D, $\mathrm{d}, \mathrm{r}$, h for a multi-stage ( 8 stage) sheet of scaling factor $1.0(\lambda=1.0)$ i.e. thickness $3.0 \mathrm{~mm}$, and the scaled cups dimensions are shown in Table 3. Figure 4 and Figure 5, shows the testing platform, tooling and the drawn parts in each stage of the multi-stage deep drawing process. Different Blank holder's materials are used in the multi-stage multi stage deep drawing mold sets for coefficient of friction shown in the Table 1 . In addition, constant the punch velocity is $100 \mathrm{~mm} / \mathrm{s}$ are applied in each stage of multi stage deep drawing process. 

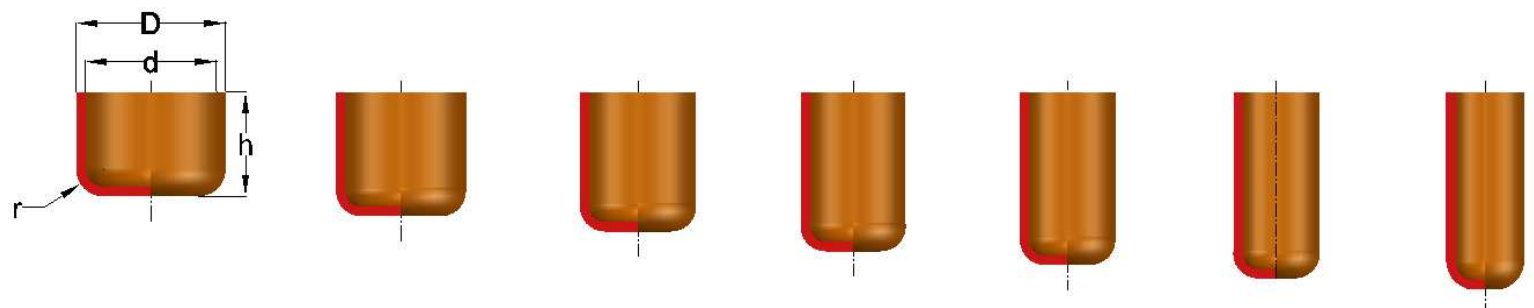

Figure 3: Cup multi-stage ( 8 stage) drawing $(\lambda=1.0)$ for sheet thickness $3.0 \mathrm{~mm}$

Table 3: The scaled proportions of the designed-cups in multi-stage with eight incremental steps

\begin{tabular}{|c|c|c|c|c|c|c|c|c|c|c|c|c|c|c|c|c|}
\hline Incremental & \multicolumn{2}{|c|}{ IS 1} & \multicolumn{2}{|c|}{ IS 2} & \multicolumn{2}{|c|}{ IS 3} & \multicolumn{2}{|c|}{ IS 4} & \multicolumn{2}{|c|}{ IS 5} & \multicolumn{2}{|c|}{ IS 6 } & \multicolumn{2}{|c|}{ IS 7} & \multicolumn{2}{|c|}{ IS 8} \\
\hline Scaled Cups & D & $\mathbf{h}$ & D & $\mathbf{h}$ & D & $\mathbf{h}$ & D & $\mathbf{h}$ & D & $\mathbf{h}$ & D & $\mathbf{h}$ & D & $\mathbf{h}$ & D & $\mathbf{h}$ \\
\hline$\lambda 1(3.0 \mathrm{~mm}$ thick $)$ & 6 & 36 & 54.72 & 43.2 & 47.68 & 48.8 & 43.2 & 55.2 & 39.36 & 60 & 35.84 & 64.8 & 32.32 & 68.8 & 29.76 & 73.6 \\
\hline$\lambda 2(1.5 \mathrm{~mm}$ thick $)$ & 3 & 18 & 27.36 & 21.6 & 23.84 & 24.4 & 21.6 & 27.6 & 19.68 & 30 & 17.92 & 32.4 & 16.16 & 34.4 & 14.88 & 36.8 \\
\hline$\lambda 3(0.75 \mathrm{~mm}$ thick $)$ & 1 & 9 & 13.68 & 10.8 & 11.92 & 12.2 & 10.8 & 13.8 & 9.84 & 15 & 8.96 & 16.2 & 8.08 & 17.2 & 7.44 & 18.4 \\
\hline$\lambda 4(0.38 \mathrm{~mm}$ thick $)$ & 7. & 4.5 & 6.84 & 5.4 & 5.96 & 6.1 & 5.4 & 6.9 & 4.92 & 7.5 & 4.48 & 8.1 & 4.04 & 8.6 & 3.72 & 9.2 \\
\hline$\lambda 5$ (0.19 $\mathrm{mm}$ thick) & 3. & 2.25 & 3.42 & 2.7 & 2.98 & 3.05 & 2.7 & 3.45 & 2.46 & 3.75 & 2.24 & 4.05 & 2.02 & 4.3 & 1.86 & 4.6 \\
\hline
\end{tabular}

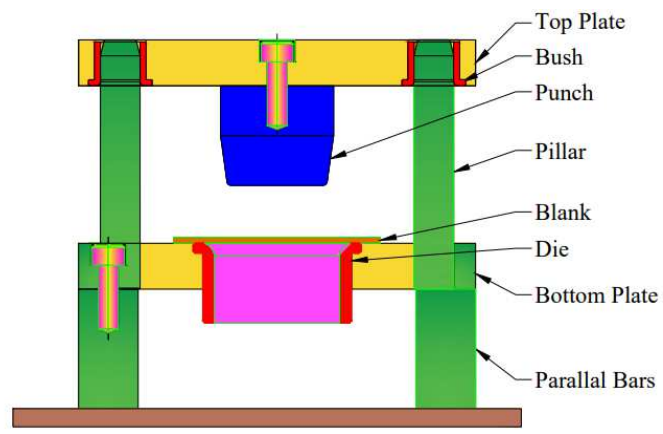

Figure 4: Schematic illustration press tool assembly operation drawing

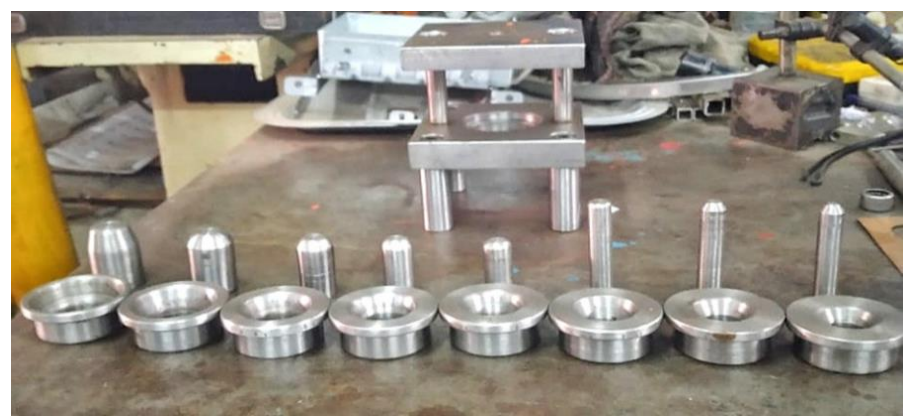

Figure 5: Illustration of the dies, showing different die sets, for

\subsubsection{AHP - (Analytic Hierarchy Process).}

AHP is one of the multiple criteria decision-making methods that were originally developed by Prof. Thomas L. Saaty [14] shown in Figure 6. It Provides measures of judgment consistency, derives priorities among criteria and alternatives, simplifies preference ratings among decision criteria using pair wise comparisons. The steps followed here are to decompose the decisionmaking problem into a hierarchy shown in Figure 7, Make the pair wise comparison using normalized values as shown in Table 9 and Table 10 to establish priorities among the elements in the hierarchy, Synthesize judgments (to obtain the set of overall or weights for achieving your goal), and Evaluate and check the consistency of judgments as shown in Table 11 .

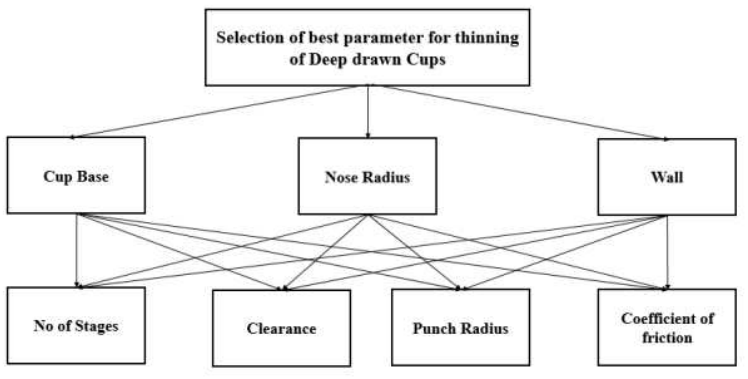

Figure 6: Hierarchy Structure of AHP

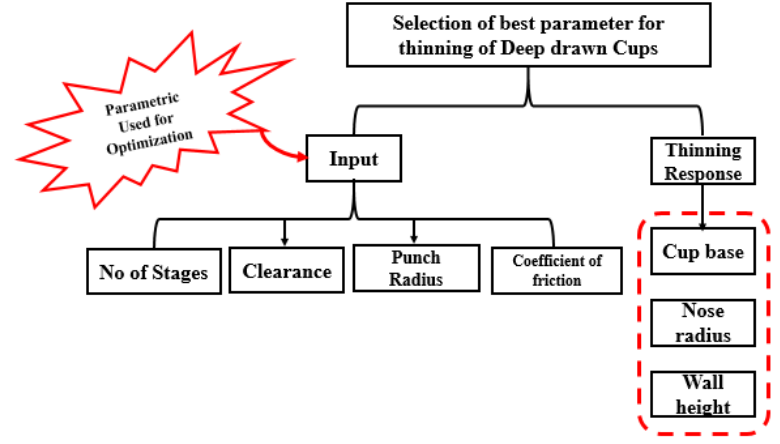

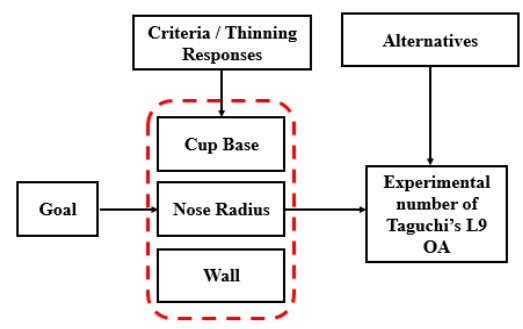

Figure 7: Hierarchy Structure of process parameters and Response

Figure 8: Process parameter and response

Table 4: variables for the ratings 


\begin{tabular}{|l|c|}
\hline \multicolumn{1}{|c|}{ Term or criteria } & Membership function or weightage \\
\hline Equal importance & 1 \\
\hline Moderate importance & 3 \\
\hline Strong importance & 5 \\
\hline Very strong importance & 7 \\
\hline Extreme importance & 9 \\
\hline Values for intermediate & $2,4,6,8$ \\
\hline
\end{tabular}

\subsubsection{Combined Compromise Solution (CoCoSo) method}

Combined compromise solution (CoCoSo) The recommended approach is based on a simple, integrated product model that is highly appreciated and highly relevant. This can be a set of commitments. The CoCoSo decision is validated to address the issue after identifying the relevant alternatives and criteria:

(1) The initial decision matrix will be determined as follows as shown in Table 11:

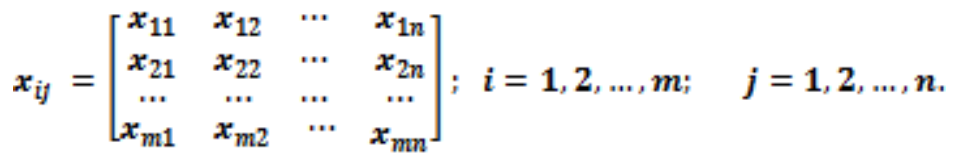

2) The normalization of criteria values is accomplished based on compromise normalization equation [16] as shown in Table 12:

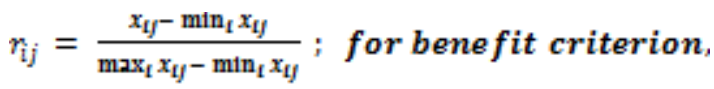

$r_{i f}=\frac{\max _{1} x_{1 y}-x_{1 y}}{\max _{1} x_{1 y}-\min _{1} x_{1 y}} ;$ for cost criterion,

(3) The total value of the comparative comparison between the weighted comparison sequence and the total weighted mean weight of the chain and the weight of each alternative to the reference density of $S_{i}$ and $P_{i}$ as shown in Table 13 and Table 14 :

This $\mathrm{Si}$ value is achieved based on grey relational generation approach:

$S_{i}=\sum_{j=1}^{n}\left(w_{j} r_{i j}\right)$,

This Pi value is also achieved according to the WASPAS multiplicative attitude.

$\boldsymbol{P}_{i}=\sum_{j=1}^{n}\left(\boldsymbol{r}_{i j}\right)^{\boldsymbol{w}_{j}}$

(4) Calculate the relative weights of alternatives using the following compilation strategies. At this stage, the relative weights of the other options obtained by formulas (6) - (8) are used to create other evaluation criteria:

$\boldsymbol{k}_{i \alpha}=\frac{P_{i}+S_{i}}{\sum_{i=1}^{m}\left(P_{i}+S_{i}\right) \mathrm{z}}$

$\boldsymbol{k}_{i b}=\frac{S_{i}}{\min _{i} S_{i}}+\frac{P_{i}}{\min _{i} P_{i}}$

$\boldsymbol{k}_{\text {ic }}=\frac{\lambda\left(S_{\mathrm{l}}\right)+(1-\lambda)\left(P_{\mathrm{l}}\right)}{\left(\lambda \max _{1} S_{\mathrm{L}}+(1-\lambda) \max _{1} P_{\mathrm{l}}\right)} ; \quad 0 \leq \lambda \leq 1$.

Equation (6) was interpreted to reflect the arithmetic mean of WSM and WPM total scores, while Equation (7) expresses the sum of the WSM and WPM relative scores for the best. Equation 8 makes a balanced compromise between WSM and WPM. In Equation (8), decision makers take $\lambda$ (usually $\lambda=0.5$ ). However, the flexibility and stability proposed by CoCoSo can be based on other values.

(5) The final ranking of the alternatives is determined based on ki, values (as more significant as better) as shown in figure 15:

$$
k_{i}=\left(k_{i a} k_{i b} k_{i c}\right)^{\frac{1}{3}}+\frac{1}{3}\left(k_{i a}+k_{i b}+k_{i c}\right)
$$

\subsubsection{Analysis of variance}

Analysis of variance (ANOVA) using the Taguchi technique, to establish the relationships between investigated process parameters and response related to thinning of cup zone, analysis of variance is carried out after numerical experimentation. Its significance of control parameters is quantified using confidence level of 95 or 99. It uses data of SNRs obtained from orthogonal arrays in Taguchi method. While Taguchi analysis shows effect levels of control parameters on quality characteristics, ANOVA represents contribution of these parameters. Therefore, it is analysis that supports and complements Taguchi analysis. So, when MEA and ANOVA combine, the most effective control factor of the forming parameters. In the course of this study, there are four main controlled variables, i.e. four factors, namely, Forming of No of Stages, Clearance, Die Radius, and Coefficient of Friction which are used for ANOVA as shown in Figure 15.

Table 5: Initial decision-making matrix X (CoCoSo)

\begin{tabular}{|c|c|l|}
\hline Symbol for Zones & Kind & \multicolumn{1}{c|}{ Criterion } \\
\hline Z1 & 1 & Thinning at Cup base \\
\hline Z2 & -1 & Thinning at Nose radius \\
\hline Z3 & 1 & Thinning at Wall \\
\hline
\end{tabular}


3.0 Results and discussion

3.1 Effects of unidirectional and bidirectional rolling on mechanical properties.

Table 6: Tensile Properties of unrolled and directionally rolled samples

\begin{tabular}{|c|c|c|c|c|c|c|c|c|c|c|c|}
\hline \multirow[t]{2}{*}{ Mechanical Property } & \multirow{2}{*}{$\begin{array}{c}\text { As } \\
\text { received } \\
\text { sheet }\end{array}$} & \multicolumn{5}{|c|}{ Uni directionally rolled } & \multicolumn{5}{|c|}{ Bi directionally rolled } \\
\hline & & $\mathrm{U} \lambda \mathbf{1}$ & $\mathrm{U} \lambda 2$ & $\mathbf{U} \lambda \mathbf{3}$ & $\mathrm{U} \lambda 4$ & $\mathrm{U} \lambda \mathbf{5}$ & $\mathbf{B} \lambda \mathbf{1}$ & $\mathbf{B} \lambda 2$ & B $\lambda 33$ & $B \lambda 4$ & B $\lambda 5$ \\
\hline Yield Strength (MPa) & 130 & 160 & 196 & 211 & 229 & 265 & 164 & 181 & 196 & 210 & 215 \\
\hline UTS (MPa) & 242 & 278 & 302 & 324 & 342 & 368 & 269 & 292 & 309 & 324 & 339 \\
\hline Elongation (\%) & 4.4 & 3.8 & 3.5 & 2.78 & 2.8 & 1.8 & 4.2 & 3.8 & 3.1 & 2.7 & 2.7 \\
\hline
\end{tabular}

Table 7: Anisotropy Properties of unrolled and directionally rolled samples

\begin{tabular}{|c|c|c|c|c|c|c|c|c|}
\hline \multirow{2}{*}{$\begin{array}{c}\text { No of } \\
\text { Stages }\end{array}$} & \multicolumn{4}{|c|}{ Uni Directional } & \multicolumn{4}{c|}{ Bi Directional } \\
\cline { 2 - 9 } & $\mathbf{U r}$ & $\mathbf{U n}$ & $\mathbf{U n r}$ & $\mathbf{U} \mathbf{\Delta r}$ & $\mathbf{B r}$ & $\mathbf{B n}$ & $\mathbf{B n r}$ & $\mathbf{B} \boldsymbol{\Delta} \mathbf{r}$ \\
\hline $\boldsymbol{\lambda} \mathbf{S 1}$ & 2.258 & 0.238 & 0.537 & 0.133 & 2.371 & 0.236 & 0.559 & 0.139 \\
\hline $\boldsymbol{\lambda} \mathbf{S 2}$ & 1.590 & 0.241 & 0.383 & 0.157 & 1.689 & 0.239 & 0.404 & 0.180 \\
\hline $\boldsymbol{\lambda} \mathbf{S 3}$ & 1.692 & 0.243 & 0.411 & 0.009 & 1.770 & 0.241 & 0.427 & 0.022 \\
\hline $\boldsymbol{\lambda} \mathbf{S 4}$ & 1.505 & 0.247 & 0.372 & 0.097 & 1.596 & 0.245 & 0.391 & 0.114 \\
\hline $\boldsymbol{\lambda} \mathbf{S 5}$ & 1.449 & 0.249 & 0.361 & 0.075 & 1.508 & 0.247 & 0.372 & 0.068 \\
\hline
\end{tabular}

The tensile and anisotropy are used as input parameters for the FEA model in order to define the yielding behavior.The yield strength of the material is in the rangebetween $160 \mathrm{MPa}$ to $265 \mathrm{MPa}$ for unidirectional rolling and $164 \mathrm{MPa}$ to 215 $\mathrm{MPa}$ for bidirectional rolling., The tensile strength of the material is in the range between $278 \mathrm{MPa}$ to $368 \mathrm{MPa}$ for unidirectional rolling and $269 \mathrm{Mpa}$ to $339 \mathrm{MPa}$ for bidirectional rolling and the total elongation percentage is in the range between $3.8 \mathrm{~mm}$ to 1.8 $\mathrm{mm}$; and $4.2 \mathrm{~mm}$ to $2.7 \mathrm{~mm}$ for unidirectional and bidirectional rolling respectively. It was found that the yield strength and the Ultimate Tensile Strength (UTS) of both unidirectional rolled copper strips and bidirectional copper strips shows an increase in the values, with a maximum increase of $22 \%$ in yield strength in stage-2 of eight-stage rolling. The UTS has a maximum increase of $8.6 \%$ also in stage 2 . Whereas a maximum reduction in the percentage elongation was observed in stage -4 , with a reduction of $20.9 \%$. Similar results were observed in bidirectional rolled copper strips.

Increase in the yield and ultimate tensile strength accompanied a reduction in the sheet thickness decreases, while it will be fair to note that tensile strength is not affected significantly and total elongation is decreased because of scaling law. Tensile testfindings available in the literature show an increasing tendencyin tensile strength and elongation due to increased sheetthickness (cross-section thickness) and there are no significantchanges in the yield strength and strain hardening exponent [19].

It was found that anisotropy increases as sheet thickness increases. It is commonly recognized that materials with high anisotropy values has high formability [r]. In this context, it was concluded that higher thickness results in higher formability capabilities. Furthermore, the planar anisotropy $(\Delta \mathrm{r})$ of experimental test results of thermally treated rolled sheets reflects that the bidirectionally rolling results in higher formability of 0.189 compared to that of 0.167 of unidirectional rolled sheets of 3 $\mathrm{mm}$ thickness. The planar isotropy value reduces for further passes of scaled rolling for both unidirection and bidirectional sheets.

Table 8: Simulation Results.

\begin{tabular}{|c|c|c|c|c|c|c|c|c|c|c|}
\hline \multirow[t]{2}{*}{ S. No } & \multirow{2}{*}{$\begin{array}{c}\text { Cleara } \\
\text { nce } \\
\text { C } \\
\end{array}$} & \multirow{2}{*}{$\begin{array}{c}\text { No of } \\
\text { Stages } \\
\text { N }\end{array}$} & \multirow{2}{*}{$\begin{array}{c}\text { Punch } \\
\text { Radius } \\
\text { R } \\
\end{array}$} & \multirow{2}{*}{$\begin{array}{c}\text { Coefficient of } \\
\text { friction } \\
\text { F }\end{array}$} & \multicolumn{2}{|c|}{$\begin{array}{c}\text { Thinning rate at Cup base, } \\
\mathrm{Z1}\end{array}$} & \multicolumn{2}{|c|}{$\begin{array}{c}\text { Thinning rate at Shoulder } \\
\text { radius, } \mathbf{Z 2}\end{array}$} & \multicolumn{2}{|c|}{ Thinning rate at Wall, $\mathbf{Z 3}$} \\
\hline & & & & & Uni & $\mathbf{B i}$ & Uni & $\mathbf{B i}$ & Uni & $\mathbf{B i}$ \\
\hline S1 & $1.5 \mathrm{t}$ & 4 & 2 & 0.1 & 9 & 12 & 16 & 22 & 4 & 12 \\
\hline S2 & $1.5 \mathrm{t}$ & 6 & 2.5 & 0.15 & 20 & 26 & 28 & 30 & 16 & 18 \\
\hline S3 & $1.5 \mathrm{t}$ & 8 & 3 & 0.2 & 15 & 21 & 66 & 58 & 22 & 29 \\
\hline S4 & $2.0 \mathrm{t}$ & 4 & 2.5 & 0.2 & 16 & 18 & 38 & 40 & 17 & 19 \\
\hline S5 & $2.0 \mathrm{t}$ & 6 & 3 & 0.1 & 24 & 28 & 68 & 62 & 28 & 32 \\
\hline S6 & $2.0 \mathrm{t}$ & 8 & 2 & 0.15 & 32 & 42 & 51 & 48 & 38 & 44 \\
\hline S7 & $2.5 \mathrm{t}$ & 4 & 3 & 0.15 & 22 & 27 & 48 & 88 & 44 & 58 \\
\hline S8 & $2.5 \mathrm{t}$ & 6 & 2 & 0.2 & 32 & 58 & 76 & 52 & 35 & 44 \\
\hline S9 & $2.5 \mathrm{t}$ & 8 & 2.5 & 0.1 & 48 & 42 & 62 & 56 & 21 & 23 \\
\hline
\end{tabular}

Table 9: Pair wise comparison matrix

\begin{tabular}{|l|l|l|l|}
\hline & $\mathrm{Z} 1$ & $\mathrm{Z} 2$ & $\mathrm{Z} 3$ \\
\hline $\mathrm{Z} 1$ & 1.0000 & 1.5000 & 1.5000 \\
\hline $\mathrm{Z} 2$ & 0.6667 & 1.0000 & 1.5000 \\
\hline $\mathrm{Z} 3$ & 0.6667 & 0.6667 & 1.0000 \\
\hline sum & 3.0000 & 3.1667 & 4.0000 \\
\hline
\end{tabular}

Table 10: Normalized Pairwise comparison matrix

\begin{tabular}{|c|c|c|c|c|}
\hline & Z1 & Z2 & Z3 & Criteria Weight \\
\hline Z1 & 0.4286 & 0.4737 & 0.3750 & 0.4258 \\
\hline Z2 & 0.2857 & 0.3158 & 0.3750 & 0.3255 \\
\hline Z3 & 0.2857 & 0.2105 & 0.2500 & 0.2487 \\
\hline sum & 1.00 & 1.00 & 1.00 & 1.0000 \\
\hline
\end{tabular}


Table 11: Calculating the consistency

\begin{tabular}{|c|c|c|c|c|c|}
\hline & Z1 & Z2 & Z3 & $\begin{array}{c}\text { Weighted } \\
\text { sum value }\end{array}$ & $\begin{array}{c}\text { Criteria } \\
\text { Weights }\end{array}$ \\
\hline Z1 & 0.4258 & 0.4883 & 0.3731 & 1.2871 & $\mathbf{0 . 4 2 5 8}$ \\
\hline Z2 & 0.2838 & 0.3255 & 0.3731 & 0.9825 & $\mathbf{0 . 3 2 5 5}$ \\
\hline Z3 & 0.2838 & 0.2170 & 0.2487 & 0.7496 & $\mathbf{0 . 2 4 8 7}$ \\
\hline & & & & $\lambda \max$ & 3.018 \\
\cline { 4 - 6 } & & & $\begin{array}{c}\text { Consistency } \\
\text { Index (C.I) }\end{array}$ & 0.00915 \\
\cline { 4 - 6 } & & & $\begin{array}{c}\text { Consistency } \\
\text { ratio }\end{array}$ & 0.0158 \\
\hline
\end{tabular}

Table 12: Initial Matrix.

\begin{tabular}{|c|c|c|c|c|c|c|}
\hline $\begin{array}{c}\text { Criteria } \\
\text { Weights }\end{array}$ & \multicolumn{2}{|c|}{$\mathbf{0 . 4 2 5 8}$} & \multicolumn{2}{c|}{$\mathbf{0 . 3 2 5 5}$} & \multicolumn{2}{c|}{$\mathbf{0 . 2 4 8 7}$} \\
\hline $\begin{array}{c}\text { kind of } \\
\text { criteria }\end{array}$ & \multicolumn{2}{|c|}{1} & \multicolumn{2}{|c|}{-1} & \multicolumn{2}{c|}{1} \\
\hline & UZ1 & BZ1 & UZ2 & BZ2 & UZ3 & BZ3 \\
\hline S1 & 9 & 12 & 16 & 22 & 4 & 12 \\
\hline S2 & 20 & 26 & 28 & 30 & 16 & 18 \\
\hline S3 & 15 & 27 & 66 & 88 & 22 & 58 \\
\hline S4 & 16 & 18 & 38 & 40 & 17 & 19 \\
\hline S5 & 24 & 28 & 68 & 62 & 28 & 32 \\
\hline S6 & 32 & 58 & 51 & 52 & 38 & 44 \\
\hline S7 & 22 & 21 & 48 & 88 & 44 & 29 \\
\hline S8 & 32 & 42 & 76 & 48 & 35 & 44 \\
\hline S9 & 48 & 42 & 62 & 56 & 21 & 23 \\
\hline
\end{tabular}

Table 13: Normalized Matrix

\begin{tabular}{|c|c|c|c|c|c|c|}
\hline \multirow{3}{*}{$\begin{array}{c}\text { weights of criteria } \\
\text { kind of criteria }\end{array}$} & \multicolumn{2}{|c|}{0.4258} & \multicolumn{2}{|c|}{0.3255} & \multicolumn{2}{|c|}{0.2487} \\
\hline & \multicolumn{2}{|c|}{1} & \multicolumn{2}{|c|}{-1} & \multicolumn{2}{|c|}{1} \\
\hline & UZ1 & BZ1 & UZ2 & BZ2 & UZ3 & BZ3 \\
\hline S1 & 0.0000 & 0.0000 & 1.0000 & 1.0000 & 0.0000 & 0.0000 \\
\hline S2 & 0.2821 & 0.3043 & 0.8000 & 0.8788 & 0.3000 & 0.1304 \\
\hline S3 & 0.1538 & 0.3261 & 0.1667 & 0.0000 & 0.4500 & 1.0000 \\
\hline S4 & 0.1795 & 0.1304 & 0.6333 & 0.7273 & 0.3250 & 0.1522 \\
\hline S5 & 0.3846 & 0.3478 & 0.1333 & 0.3939 & 0.6000 & 0.4348 \\
\hline S6 & 0.5897 & 1.0000 & 0.4167 & 0.5455 & 0.8500 & 0.6957 \\
\hline S7 & 0.3333 & 0.1957 & 0.4667 & 0.0000 & 1.0000 & 0.3696 \\
\hline S8 & 0.5897 & 0.6522 & 0.0000 & 0.6061 & 0.7750 & 0.6957 \\
\hline S9 & 1.0000 & 0.6522 & 0.2333 & 0.4848 & 0.4250 & 0.2391 \\
\hline
\end{tabular}

The next step is to create a matrix of the comparison sequence. In this process, decision tables are involved in decision criteria in algorithms. With Table 14, the vectors $S_{i}$ and $P_{i}$ should be created according to formulas (4) and (5), respectively. The values obtained are shown in Tables 13 and 14. Repeat strategies are needed to get the final result. At this stage, the $K_{a}, K_{b}$ and $K_{c}$ values are derived using equations (7), (8) and (9). Verification of alternatives is based on these $\mathrm{k}$ values. Equation (10) produces the $\mathrm{k}$ point of rank to find the final mark of the options. This vector appears in Table 16. The scaling factor ranks are shown in the Table 18.

Table 14: Weighted comparability sequence and $\mathrm{Si}$

\begin{tabular}{|c|c|c|c|c|c|c|c|c|}
\hline & UZ1 & BZ1 & UZ2 & BZ2 & UZ3 & BZ3 & USi & BSi \\
\hline S1 & 0.0000 & 0.0000 & 0.3255 & 0.3255 & 0.0000 & 0.0000 & $\mathbf{0 . 3 2 5 5}$ & $\mathbf{0 . 3 2 5 5}$ \\
\hline S2 & 0.1201 & 0.1296 & 0.2604 & 0.2860 & 0.0746 & 0.0324 & $\mathbf{0 . 4 5 5 1}$ & $\mathbf{0 . 4 4 8 1}$ \\
\hline S3 & 0.0655 & 0.1388 & 0.0543 & 0.0000 & 0.1119 & 0.2487 & $\mathbf{0 . 2 3 1 7}$ & $\mathbf{0 . 3 8 7 5}$ \\
\hline S4 & 0.0764 & 0.0555 & 0.2062 & 0.2367 & 0.0808 & 0.0378 & $\mathbf{0 . 3 6 3 4}$ & $\mathbf{0 . 3 3 0 1}$ \\
\hline S5 & 0.1638 & 0.1481 & 0.0434 & 0.1282 & 0.1492 & 0.1081 & $\mathbf{0 . 3 5 6 4}$ & $\mathbf{0 . 3 8 4 5}$ \\
\hline S6 & 0.2511 & 0.4258 & 0.1356 & 0.1775 & 0.2114 & 0.1730 & $\mathbf{0 . 5 9 8 1}$ & $\mathbf{0 . 7 7 6 4}$ \\
\hline S7 & 0.1419 & 0.0833 & 0.1519 & 0.0000 & 0.2487 & 0.0919 & $\mathbf{0 . 5 4 2 5}$ & $\mathbf{0 . 1 7 5 2}$ \\
\hline S8 & 0.2511 & 0.2777 & 0.0000 & 0.1973 & 0.1927 & 0.1730 & $\mathbf{0 . 4 4 3 9}$ & $\mathbf{0 . 6 4 8 0}$ \\
\hline S9 & 0.4258 & 0.2777 & 0.0760 & 0.1578 & 0.1057 & 0.0595 & $\mathbf{0 . 6 0 7 4}$ & $\mathbf{0 . 4 9 5 0}$ \\
\hline
\end{tabular}

Table 15: Exponentially weighted comparability sequence and $\mathrm{Pi}$

\begin{tabular}{|c|c|c|c|c|c|c|c|c|}
\hline & UZ1 & BZ1 & UZ2 & BZ2 & UZ3 & BZ3 & UPi & BPi \\
\hline S1 & 0.0000 & 0.0000 & 1.0000 & 1.0000 & 0.0000 & 0.0000 & 1.0000 & 1.0000 \\
\hline S2 & 0.5834 & 0.6026 & 0.9299 & 0.9588 & 0.7412 & 0.6026 & 2.2546 & 2.1640 \\
\hline S3 & 0.4507 & 0.6206 & 0.5581 & 0.0000 & 0.8199 & 1.0000 & 1.8287 & 1.6206 \\
\hline S4 & 0.4812 & 0.4201 & 0.8618 & 0.9015 & 0.7561 & 0.6261 & 2.0992 & 1.9477 \\
\hline S5 & 0.6657 & 0.6378 & 0.5190 & 0.7384 & 0.8807 & 0.8129 & 2.0654 & 2.1892 \\
\hline S6 & 0.7986 & 1.0000 & 0.7520 & 0.8209 & 0.9604 & 0.9137 & 2.5111 & 2.7346 \\
\hline S7 & 0.6264 & 0.4992 & 0.7803 & 0.0000 & 1.0000 & 0.7807 & 2.4067 & 1.2799 \\
\hline S8 & 0.7986 & 0.8336 & 0.0000 & 0.8496 & 0.9386 & 0.9137 & 1.7372 & 2.5969 \\
\hline S9 & 1.0000 & 0.8336 & 0.6227 & 0.7901 & 0.8083 & 0.7006 & 2.4310 & 2.3243 \\
\hline
\end{tabular}

Table 16: Final Aggregation and Ranking $\lambda=0.5$

\begin{tabular}{|c|c|c|c|c|c|c|c|c|c|c|c|c|c|c|c|c|}
\hline \multirow{2}{*}{$\begin{array}{c}\text { Alter } \\
\text { nativ } \\
\text { es }\end{array}$} & \multicolumn{2}{|c|}{ Ka } & \multicolumn{2}{|c|}{ Ranking } & \multicolumn{2}{|c|}{$\mathrm{Kb}$} & \multicolumn{2}{|c|}{ Ranking } & \multicolumn{2}{|c|}{$\mathrm{Kc}$} & \multicolumn{2}{|c|}{ Ranking } & \multicolumn{2}{|c|}{ K } & \multicolumn{2}{|c|}{$\begin{array}{c}\text { Final } \\
\text { Ranking }\end{array}$} \\
\hline & $\mathbf{U}$ & B & $\mathbf{U}$ & B & $\mathbf{U}$ & B & $\mathbf{U}$ & B & $\mathbf{U}$ & B & $\mathbf{U}$ & B & $\mathbf{U}$ & B & $\mathbf{U}$ & B \\
\hline S1 & 0.0596 & 0.0607 & 9 & 9 & 2.4050 & 2.8577 & 9 & 8 & 0.4250 & 0.3775 & 9 & 9 & 1.3566 & 1.5018 & 9 & 8 \\
\hline S2 & 0.1217 & 0.1197 & 4 & 4 & 4.2190 & 4.7212 & 4 & 4 & 0.8689 & 0.7440 & 4 & 4 & 2.5007 & 2.6107 & 4 & 4 \\
\hline S3 & 0.0926 & 0.0920 & 8 & 7 & 2.8287 & 3.8323 & 8 & 6 & 0.6607 & 0.5719 & 8 & 7 & 1.7512 & 2.0852 & 8 & 7 \\
\hline S4 & 0.1106 & 0.1044 & 5 & 6 & 3.6678 & 3.8317 & 5 & 7 & 0.7897 & 0.6488 & 5 & 6 & 2.2070 & 2.1661 & 5 & 6 \\
\hline
\end{tabular}




\begin{tabular}{|l|l|l|l|l|l|l|l|l|l|l|l|l|l|l|l|l|}
\hline S5 & 0.1088 & 0.1179 & 6 & 5 & 3.6038 & 4.3834 & 7 & 5 & 0.7766 & 0.7330 & 6 & 5 & 2.1692 & 2.4683 & 6 & 5 \\
\hline S6 & 0.1397 & 0.1609 & 1 & 1 & 5.0929 & 7.1654 & 1 & 1 & 0.9970 & 1.0000 & 1 & 1 & 2.9683 & 3.8239 & 1 & 1 \\
\hline S7 & 0.1325 & 0.0667 & 3 & 8 & 4.7485 & 2.2799 & 3 & 9 & 0.9457 & 0.4145 & 3 & 8 & 2.7833 & 1.3183 & 3 & 9 \\
\hline S8 & 0.0980 & 0.1487 & 7 & 2 & 3.6531 & 6.2950 & 6 & 2 & 0.6994 & 0.9242 & 7 & 2 & 2.1138 & 3.4087 & 7 & 2 \\
\hline S9 & 0.1365 & 0.1292 & 2 & 3 & 5.0530 & 5.1492 & 2 & 3 & 0.9743 & 0.8030 & 2 & 3 & 2.9306 & 2.8384 & 2 & 3 \\
\hline
\end{tabular}

Table 16, indicates that S6 is the best processing parameter and that service provider S1/7 is the worst alternative. This approach is quite certain if the final classification for each final classification of $\mathrm{k}$ and Final $\mathrm{k}$ is the highest. The note indicates that the final sequence and each sequence are the same. Thus, the evaluation decision on the issue of choosing a forming process parameter

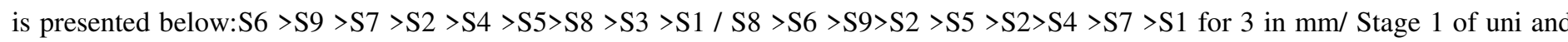
bidirectional rolled sample so this ranking will met the objective of the study. Like the same procedure followed by the subsequent stages to get the rank and ANNOVA results and verified the scaling law.
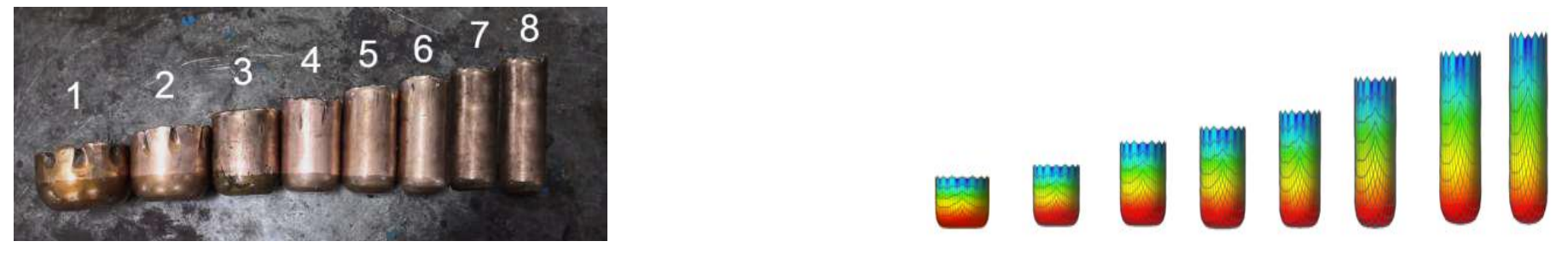

Figure 9: Optimizied Experimental and FEA Formed cups $(\chi=1)$

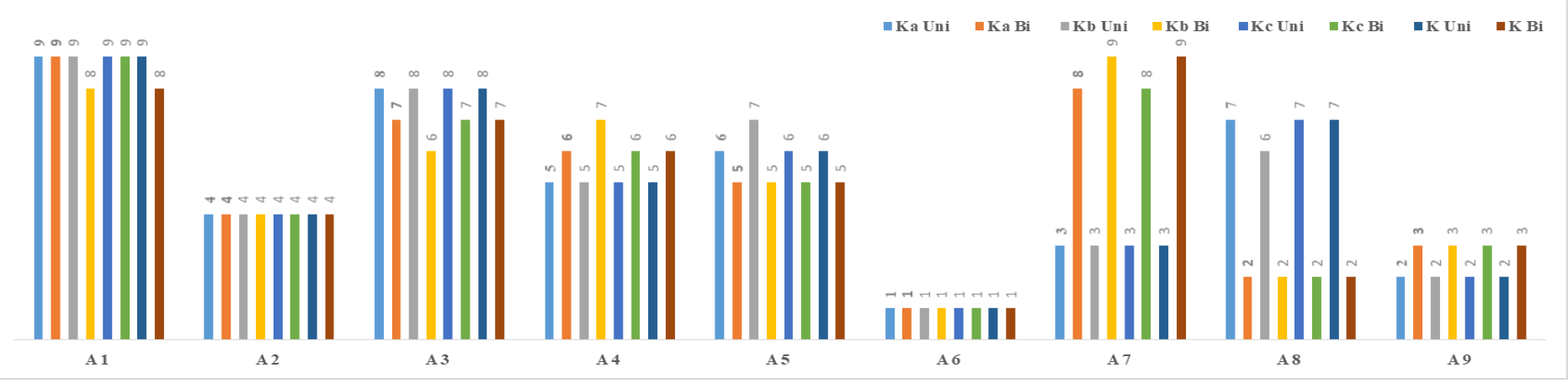

Figure 10: Comparison k values.

The objective of the study is appropriate for a new approach to MCDM. The article presents a new strategy for solving the MCDM problem with some specific modifications in the structure. To achieve this goal, calculate the values of the measured standards; follow the weighted comparison and the exponential weight of the comparison sequence for each specific alternative. Three aggregation strategies are created to form a complete measure. The aggregate assembly is provided as appropriate and the rate of optimum rating. The comparison of these three indicators may be linked to alternative priorities. The CoCoSo algorithm was also confirmed by some comparative analysis and evidence. The results of only one simulation for $3.0 \mathrm{~mm}$ thick blank, rolled unidirectionally, and bidirectionally is alone presented owing to space considerations, whereas, the others can be found from the supplementary data provided.

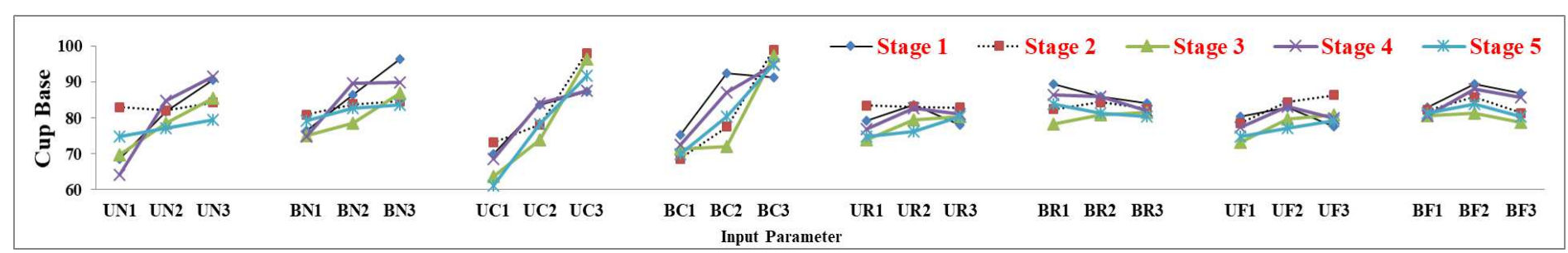

Figure 11: Effects on Cup base Uni and bi directional sample.

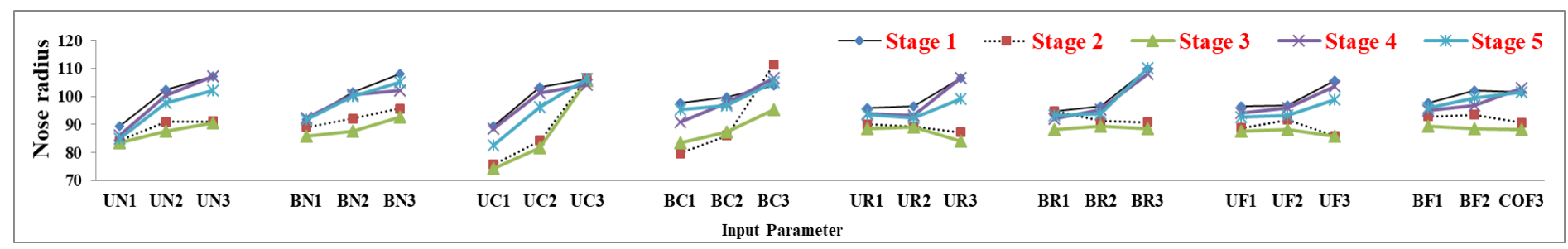

Figure 12: Effects on shoulder radius Uni and bi directional sample.

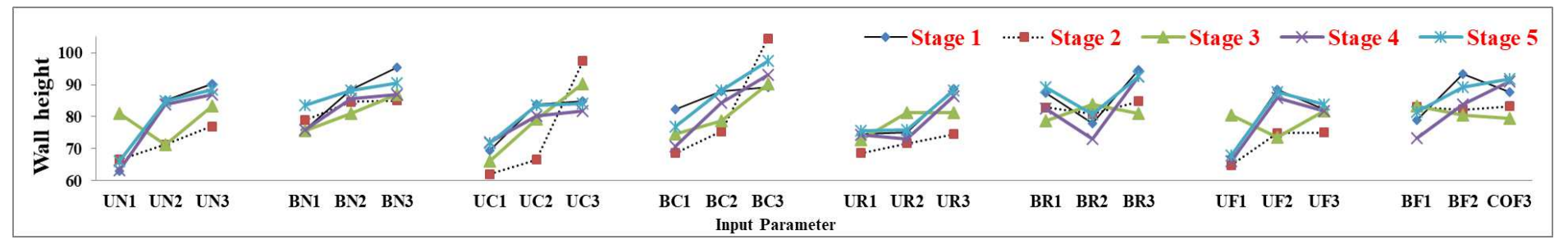

Figure 13: Effects on Wall height Uni and bi directional sample. 


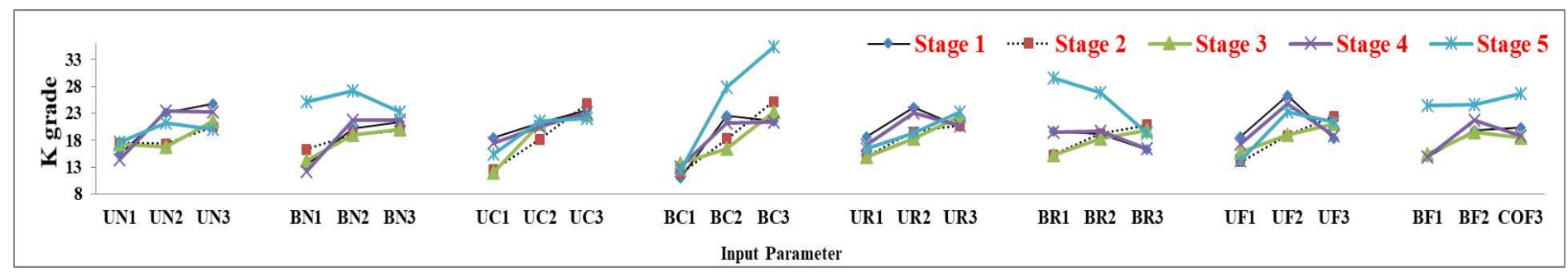

Figure 14: Effects on K Grades Uni directional and bi directional rolled sample.

Table 17: Optimal Setting of Parameters Individual effects

\begin{tabular}{|c|c|c|c|c|c|c|c|c|}
\hline \multirow{2}{*}{$\begin{array}{c}\text { Quality } \\
\text { Characteristics } \\
\text { or responses }\end{array}$} & \multicolumn{2}{|c|}{ Cup Base } & \multicolumn{2}{|c|}{ Nose Radius } & \multicolumn{2}{|c|}{ Wall Height } & \multicolumn{2}{|c|}{ K Grade } \\
\hline & $\mathbf{U}$ & B & $\mathbf{U}$ & B & $\mathbf{U}$ & B & $\mathbf{U}$ & B \\
\hline$\lambda_{1}$ & $\mathrm{~N} 3, \mathrm{C} 3, \mathrm{P} 2, \mathrm{C} 2$ & $\mathrm{~N} 3, \mathrm{C} 2, \mathrm{P} 1, \mathrm{C} 2$ & $\mathrm{~N} 3, \mathrm{C} 3, \mathrm{P} 3, \mathrm{C} 3$ & $\mathrm{~N} 3, \mathrm{C} 3, \mathrm{P} 3, \mathrm{C} 2$ & $\mathrm{~N} 3, \mathrm{C} 3, \mathrm{P} 3, \mathrm{C} 3$ & $\mathrm{~N} 3, \mathrm{C} 3, \mathrm{P} 3, \mathrm{C} 2$ & $\mathrm{~N} 3, \mathrm{C} 3, \mathrm{P} 1, \mathrm{C} 3$ & $\mathrm{~N} 3, \mathrm{C} 2, \mathrm{P} 1, \mathrm{C} 3$ \\
\hline$\lambda 2$ & $\mathrm{~N} 3, \mathrm{C} 3, \mathrm{P} 1, \mathrm{C} 3$ & $\mathrm{~N} 3, \mathrm{C} 3, \mathrm{P} 2, \mathrm{C} 2$ & $\mathrm{~N} 3, \mathrm{C} 3, \mathrm{P} 1, \mathrm{C} 3$ & $\mathrm{~N} 3, \mathrm{C} 3, \mathrm{P} 1, \mathrm{C} 3$ & $\mathrm{~N} 3, \mathrm{C} 3, \mathrm{P} 3, \mathrm{C} 3$ & $\mathrm{~N} 3, \mathrm{C} 3, \mathrm{P} 3, \mathrm{C} 3$ & $\mathrm{~N} 3, \mathrm{C} 3, \mathrm{P} 3, \mathrm{C} 3$ & $\mathrm{~N} 3, \mathrm{C} 3, \mathrm{P} 3, \mathrm{C} 3$ \\
\hline$\lambda 3$ & $\mathrm{~N} 3, \mathrm{C} 3, \mathrm{P} 3, \mathrm{C} 3$ & $\mathrm{~N} 3, \mathrm{C} 3, \mathrm{P} 3, \mathrm{C} 2$ & $\mathrm{~N} 3, \mathrm{C} 3, \mathrm{P} 1, \mathrm{C} 2$ & $\mathrm{~N} 3, \mathrm{C} 3, \mathrm{P} 3, \mathrm{C} 1$ & $\mathrm{~N} 3, \mathrm{C} 3, \mathrm{P} 3, \mathrm{C} 3$ & $\mathrm{~N} 3, \mathrm{C} 3, \mathrm{P} 2, \mathrm{C} 1$ & $\mathrm{~N} 3, \mathrm{C} 3, \mathrm{P} 3, \mathrm{C} 3$ & $\mathrm{~N} 3, \mathrm{C} 3, \mathrm{P} 3, \mathrm{C} 2$ \\
\hline$\lambda 4$ & $\mathrm{~N} 3, \mathrm{C} 3, \mathrm{P} 2, \mathrm{C} 1$ & $\mathrm{~N} 3, \mathrm{C} 3, \mathrm{P} 1, \mathrm{C} 2$ & $\mathrm{~N} 3, \mathrm{C} 2, \mathrm{P} 3, \mathrm{C} 3$ & $\mathrm{~N} 3, \mathrm{C} 3, \mathrm{P} 3, \mathrm{C} 3$ & $\mathrm{~N} 3, \mathrm{C} 2, \mathrm{P} 3, \mathrm{C} 2$ & $\mathrm{~N} 3, \mathrm{C} 3, \mathrm{P} 3, \mathrm{C} 3$ & $\mathrm{~N} 2, \mathrm{C} 3, \mathrm{P} 2, \mathrm{C} 2$ & $\mathrm{~N} 3, \mathrm{C} 3, \mathrm{P} 2, \mathrm{C} 2$ \\
\hline$\lambda 5$ & $\mathrm{~N} 3, \mathrm{C} 3, \mathrm{P} 3, \mathrm{C} 3$ & $\mathrm{~N} 3, \mathrm{C} 3, \mathrm{P} 1, \mathrm{C} 2$ & $\mathrm{~N} 3, \mathrm{C} 2, \mathrm{P} 3, \mathrm{C} 3$ & $\mathrm{~N} 3, \mathrm{C} 3, \mathrm{P} 3, \mathrm{C} 3$ & $\mathrm{~N} 3, \mathrm{C} 3, \mathrm{P} 3, \mathrm{C} 2$ & $\mathrm{~N} 3, \mathrm{C} 3, \mathrm{P} 3, \mathrm{C} 3$ & $\mathrm{~N} 2, \mathrm{C} 3, \mathrm{P} 3, \mathrm{C} 3$ & $\mathrm{~N} 1, \mathrm{C} 3, \mathrm{P} 1, \mathrm{C} 3$ \\
\hline
\end{tabular}
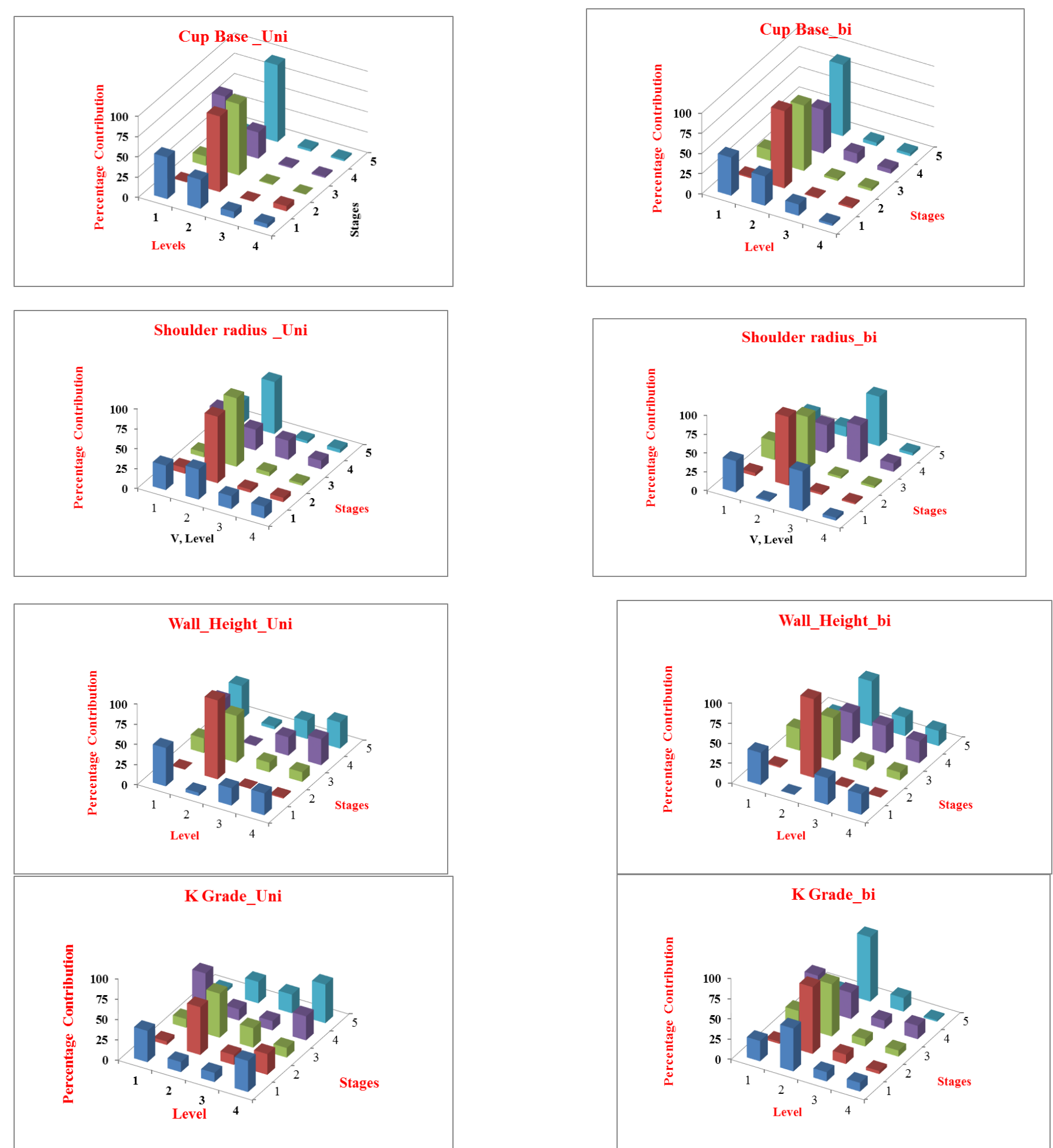

Figure 15: (a), (b), Percentage Contribution for scaling factor on direction of rolling

Table 18: Scaling factor ranks.

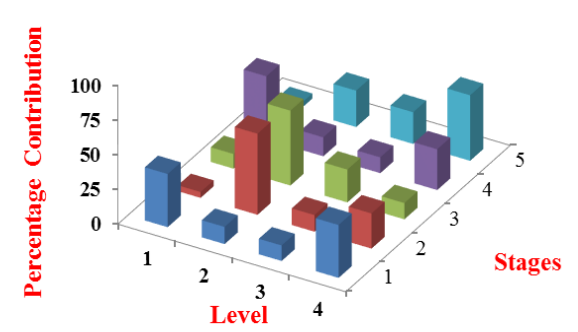

Bi Directional

$\lambda 5$

Uni Directional

\begin{tabular}{l|l|l}
$\lambda 3$ & $\lambda 2$ & $\lambda 1$
\end{tabular}

$\lambda 1$

$\lambda 4$

\begin{tabular}{l|l}
$\lambda 3$ & $\lambda 2$
\end{tabular}




\begin{tabular}{|l|l|l|l|l|l|l|l|l|l|l|}
\hline S1 & 9 & 9 & 9 & 9 & 9 & 8 & 9 & 9 & 9 & 8 \\
\hline S2 & 4 & 5 & 5 & 4 & 4 & 5 & 4 & 8 & 6 & 4 \\
\hline S3 & 1 & 8 & 1 & 1 & 8 & 4 & 8 & 3 & 1 & 7 \\
\hline S4 & 7 & 4 & 8 & 7 & 5 & 7 & 6 & 7 & 8 & 6 \\
\hline S5 & 5 & 6 & 4 & 8 & 6 & 6 & 5 & 5 & 4 & 5 \\
\hline S6 & 2 & 1 & 7 & 5 & 1 & 1 & 1 & 1 & 3 & 1 \\
\hline S7 & 3 & 3 & 6 & 6 & 3 & 9 & 7 & 4 & 7 & 9 \\
\hline S8 & 6 & 7 & 3 & 3 & 7 & 3 & 2 & 6 & 5 & 2 \\
\hline S9 & 8 & 2 & 2 & 2 & 2 & 2 & 3 & 2 & 2 & 3 \\
\hline
\end{tabular}

\subsection{Determination of weightage by AHP:}

The weighted values of the criteria were assigned using the scale developed by Satty [14] and consequently a pair-wise comparison matrix was established to determine decision criteria in a hierarchical tree structure at different levels using AHP in Table 7, resulting in the final weight of each criterion Table 11, with consistency ratio. The results of implementing AHP model in the case under consideration are represented in Tables from Table 9-11. The relative importance of the attributes through pair-wise comparison is represented in Table 9, using membership functions based on the guidelines in Table 4. Based on the pair wise comparison in Table 9, the priority weights of attributes are calculated as per satty rule [14]. The other three factors have been assigned comparatively lesser importance as per the requirements of the present case under consideration. After the calculation of attribute weights, the pairwise comparison of forming processes is to be carried out with respect to each of the attribute to arrive at their scores in the direction of these attributes. Relative comparisons were made based on the research previously reported and expert experience. After assigning weight to each criterion using the AHP approach the places that were considered potentially suitable for a study of process parameters were ranked using the CoCoSO method: Construction of a decision matrix (DM) using Step3 of the forming and its selection process (Table 1), and the Calculation of the normalized decision matrix as per standardize procedure. From the table 10, proves that, the Consistency Ratio is less than $10 \%$, the subjective judgment is accepted. Hence, the weights of the criteria are $0.4258,0.3255$, and 0.2487 respectively.

\subsection{Determination of optimum input parameter by CoCoSo:}

According to the simulation response data on the criteria describing themaximumthinning rate of the parts (Cup Bottom, Nose radius and Cup wall) can be made. The studies performed help to identify the best process parameter for getting better quality of products for rejection and to developing and implementing measures aimed at increasing the Product Quality for the benefits of customers. The results obtained (quality ratio with an optimal parameter alternative according to its rank) represent characteristics with some error. The study of the Optimum Process parameter of the obtained data with the values provided by the response data and allowed us to state that most of the investigated parameters do not meet the current specifications. Priority order for Uni and $\mathrm{Bi}$ directional sample of the investigated trails can be represented as: $\mathrm{S} 6>\mathrm{S} 9>\mathrm{S} 7>\mathrm{S} 2>\mathrm{S} 4>\mathrm{S} 5>\mathrm{S} 8>\mathrm{S} 3>\mathrm{S} 1 / \mathrm{S} 8>\mathrm{S} 6>\mathrm{S} 9>\mathrm{S} 2>\mathrm{S} 5>\mathrm{S} 2>\mathrm{S} 4$ $>\mathrm{S} 7>\mathrm{S} 1$ for $3 \mathrm{in} \mathrm{mm} /$ Stage 1 of uni and bidirectional rolled sample. From the above training data, it means that the best Process parameter and optimal solution is in forming trails no 6/8.No of Stages of 6/8, Clearance of 2.5t/2.0t in mm, Punch Radius of 3/2.5 in $\mathrm{mm}$, and Coefficient of friction 0.15/0.10.Correspondingly listed in rank for another scaling factor in Table 15 for both the samples is the optimal solution as shown in Table 16.

\subsection{ANOVA analysis of forming parameters:}

Forming process parameters can be investigated by ANOVA to verify the parameters that significantly influenced the quality characteristic in table 17. The ANOVA was carried out and the results were shown in Figure 15. The main objective of percentage contributions is to analyze the parameters which significantly affect the performance characteristics. The larger value of percentage contributions means that the factor has a greater influence of better products on the response variable.

Based on the experimental results, the direction for forming parameters using Uni and bi directional sample is studied in order to reach the desired outputs. No of stages has a strong effect on maintain the Cup base, nose radius and Wall height in both the sample, followed by clearance, the ranking grade also obeys the No of stages and clearance as shown in Figure 15.

\subsection{The Interaction Effects among the Variables}

The Interaction Effects of Thinning of both the samples. The Optimal Setting of Parameters effects and their Values obtained by Single Objective Optimization. While considering the No of stages, in this the level 3, No of stages plays a vital role for getting a better product quality, why because the stress concentration will act equally from that thinning will be uniform. In Clearance of 2 and 3 plays a major contribution, it has a better material flow and thinning is optimum, while considering the punch nose radius will contribute the all 3-radius maximum, why because the rate of thinning increase is less for lower values of punch nose radius. A generous die shoulder radius provides minimum resistance to flow of material during drawing. The larger punch nose radius allows the material to be easily drawn in to the die cavity, thereby reducing the extent of stretching along the cup wall. The same results observed from the Figure 11 to Figure 15. 


\subsection{Model Sensitivity analysis:}

Doing a sensitivity analysis is to validate the results and justify the accuracy and deviation of the decision outcomes. It could help decision-makers to prove their method outcomes by some changes in the primary model. Here, we perform a weight replacement strategy for that purpose. It is to validate the results and justify the accuracy and deviation of the decision outcomes. A sensitivity analysis test could help decision-makers to prove their method for best process parameters outcomes by some changes in the primary model. The sensitivity analysis and validated of the proposed Combined AHP-CoCoSo, and MCDM model was done by interchanging the weights of the criterions, and subsequently, the ranks of the alternatives were obtained. In the present experiment, three combinations were selected namely $\mathrm{C} 1, \mathrm{C} 2$, and C3. C1 was made by interchanging the weights of Cup base with weight of Shoulder radius, $\mathrm{C} 2$ was made by interchanging the weight of Shoulder radius with Wall height, and C3 was made without interchanging the weights i.e. Wall height.The ranks of all combinations are listed in Figure 16. This proves the contribution of the proposed algorithm cause its results are very similar to the experimental results and model sensitivity also verified.

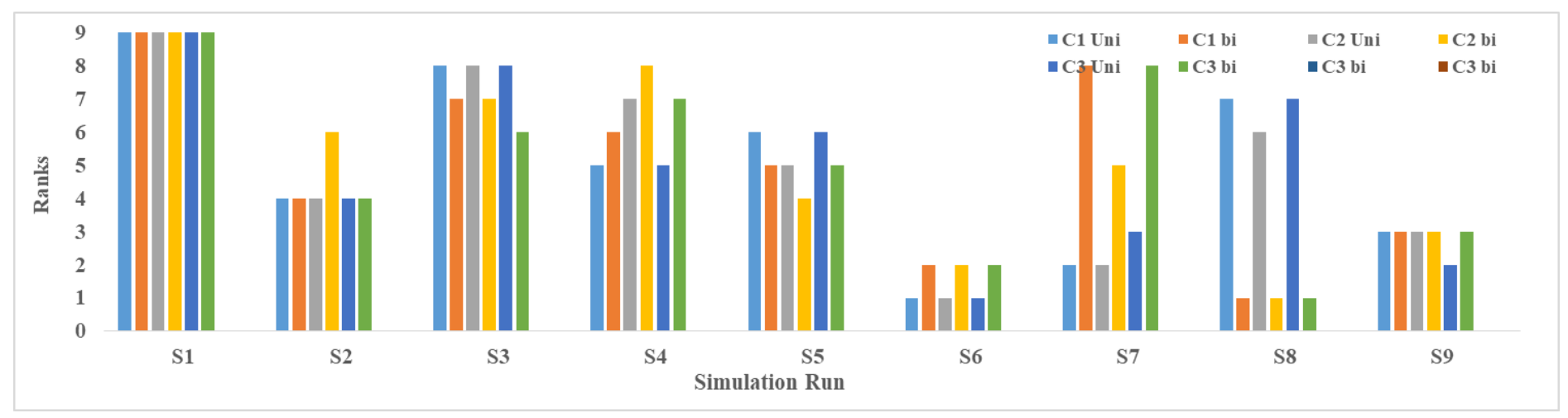

Figure 16: Sensitivity analysis

\subsection{Model validation via experimental:}

The last stage in Taguchi optimization method is to conduct confirmation experiments with the optimum combination of influencing factors for validating the improvement in the response variable by comparing it with the original baseline condition. The Optimum Process parameter of the obtained data with the values provided by the experiments and allowed us to state that most of the investigated parameters meet the current specifications. Priority order for Uni and Bi directional sample of the investigated trails can be represented as: $\mathrm{S} 6>\mathrm{S} 9>\mathrm{S} 7>\mathrm{S} 2>\mathrm{S} 4>\mathrm{S} 5>\mathrm{S} 8>\mathrm{S} 3>\mathrm{S} 1 / \mathrm{S} 8>\mathrm{S} 6>\mathrm{S} 9>\mathrm{S} 2>\mathrm{S} 5>\mathrm{S} 2>\mathrm{S} 4>\mathrm{S} 7>\mathrm{S} 1$. The experimental trails was done by the optimum process parameter with No of stages 8 , Clearance of $2.5 \mathrm{t}$, punch radius of $3 \mathrm{in} \mathrm{mm,} \mathrm{and} \mathrm{CoF} 0.2 / \mathrm{No}$ of stages 8 , Clearance of $2 \mathrm{t}$, punch radius of 3 in $\mathrm{mm}$, and $\mathrm{CoF} 0.2$, for both the samples, with standard hydraulic press and calibration was done by Tex-913-K shown in figure 4, 5. The experiment proves that for the optimal parameters like No of stages 8 of, Clearance of $2 . t$, punch radius of 2 in $\mathrm{mm}$, and CoF 0.15 for rolled directional sample with uni and bi sample of cup base 32/42, shoulder radius of 51/48, and wall height 38/44.Since, 3 trails were taken by the optimum conditions of the experiment response fairly close to the simulated results, so results and model would be satisfactory for this study.

\subsection{Conclusions}

In the present work, forming process by multi stage deep drawingon together with the AHP coupled with Taguchi CoCoSo and the ANOVA technique was used to investigate the combined effect of parameterswith robust Taguchi design of simulation and confirmation experimental in the study. The following conclusions are drawn from the investigation. The goal of this study is pertinent to a new approach in the MCDM domain. The paper proposes a new strategy to solve an AHP coupled with Taguchi CoCoSo and the ANOVA technique through some specific modification to the main structure. To head to that goal, AHP was determined by individual response weights, calculation of normalised criteria values, weighted comparability sequence, and the exponential weight of comparability sequences for each alternative identified. Then, three aggregator strategies are established to form a complete measure. Generating of the relevant and adjusted aggregator to reach optimal rank index has been presented. An equation can correlate those three rank indexes ultimately, and alternative priorities are obtained. The problem of forming process by multi stage multi step deep drawing process by scaling effects to examined the performance of the proposed model. By some comparative analysis and through the evidence, the stability of the CoCoSo model is also approved. Implementing and applying thistechnique not only increases the accuracy of the decision-makingsystem. This study indicates that A6 is the best processing parameter and that service provider S1/7 is the worst alternative. By using Taguchi analysis; most effective control parameters on both and all the scaling samples were found to be No of Stages, clearance, punch radius and Coefficient of friction respectively. In addition, optimum combinations of control parameters affecting both the samples were determined with all the scaled cups. ANOVA results showed that the No of stages had a very dominant effect on both the samples with highest product quality.

\section{References.}

1. L.F. Peng, X.M. Lai, H.J. Lee, J.H. Song, J. Ni, Analysis of micro/mesoscale sheet forming process with uniform size dependent material constitutive model, Materials science and Engineering: A 526(1) (2009) 93-99. 
2. W. Chan, M.W. Fu, B. Yang, Study of size effect in micro-extrusion process of pure copper, Materials \& Design 32(7) (2011) 3772-3782.

3. M.W. Fu, B. Yang, W.L. Chan, Experimental and simulation studies of micro blanking and deep drawing compound process using copper sheet, Journal of Materials Processing Technology 213(1) (2013) 101-110.

4. M. Thome, G. Hirt, B. Rattay, Metal flow and die filling in coining of micro structures with and without flash, Advanced Materials Research 6-8 (2005) 631-638.

5. A.R. Razali, Y. Qin, A review on micro-manufacturing, micro-forming and their key issues, Procedia Engineering 53 (2013) $665-$ 672.

6. L. Zheng Bao, "CAE technique of sheet metal forming for automotive body panels", National University of Defense Technology Press, 2003.

7. Zavadskas, E.K., Kaklauskas, A., Turskis, Z. and Kalibatas, D. (2009), "An approach to multi-attribute assessment of indoor environment before and after refurbishment of dwellings", Journal of Environmental Engineering and Landscape Management, Vol. 17 No. 1, pp. 5-11.

8. Zavadskas, E.K., Turskis, Z. and Kildienè, S. (2014), "State of art surveys of overviews on MCDM/MADM methods", Technological and Economic Development of Economy, Vol. 20 No. 1, pp. 165-179.

9.Šaparauskas, J., Zavadskas, E.K. and Turskis, Z. (2011), "Selection of facade's alternatives of commercial and public buildings based on multiple criteria", International Journal of Strategic Property Management, Vol. 15 No. 2, pp. 189-203.

10. Kochen, M., MacKay, D.M., Moran, M.E., Scriven, M. and Uhr, L. (1967), "Computers and comprehension. RAND memorandum. RM-4065-PR", in Kochen, M. (Ed.), The Growth of Knowledge, Wiley, New York, NY.

11. Ho, W., Xu, X. and Dey, P.K. (2010), "Multi-criteria decision-making approaches for supplier evaluation and selection: a literature review", European Journal of Operational Research, Vol. 202 No. 1, pp. 16-24.

12. Franklin, B. (1772), "Letter to Joseph Priestley, Fawcett, New York, NY", Reprinted in the Benjamin Franklin Sampler (1956).

13. Zeleny, M. (1975), "MCDM - state and future of arts", Operations Research, Vol. 23 No. S2, p. B413.

14. T.L. Saaty, Analytic hierarchy process, McGraw Hill Publications, New York, 1980.

15. F. Deniz, Optimization of methyl orange bioremoval by Prunus amygdalus L. (almond) shell waste: Taguchi methodology approach and biosorption system design, Desalin. Water Treat. 51 (2013) 7067-7073.

16. ASTM E8/E8M-11, Standard Test Methods for Tension Testing of Metallic Materials, ASTM International, West Conshohocken, PA, 2011.

Availability of data and materials.

The authors confirm that the data supporting the findings of this study are available within the article.

\section{Competing interests.}

I declare that I have no significant competing financial, professional, or personal interests that might have influenced the performance or presentation of the work described in this manuscript.

\section{Declaration of Conflicting Interests}

The author(s) declared no potential conflicts of interest with respect to the research, authorship, and/or publication of this article

\section{Funding}

No Funding (NA)

\section{Authors' contributions}

Both the Authors have done the following tasks such as design of the work, Data collection, Data analysis and interpretation, Drafting the article, Critical revision of the article, Final approval of the version to be published

\section{Acknowledgements}

We would like to express our sincere gratitude to Altair for permitting us to use their software and providing their technical support for completion of the work. 


\section{Figures}

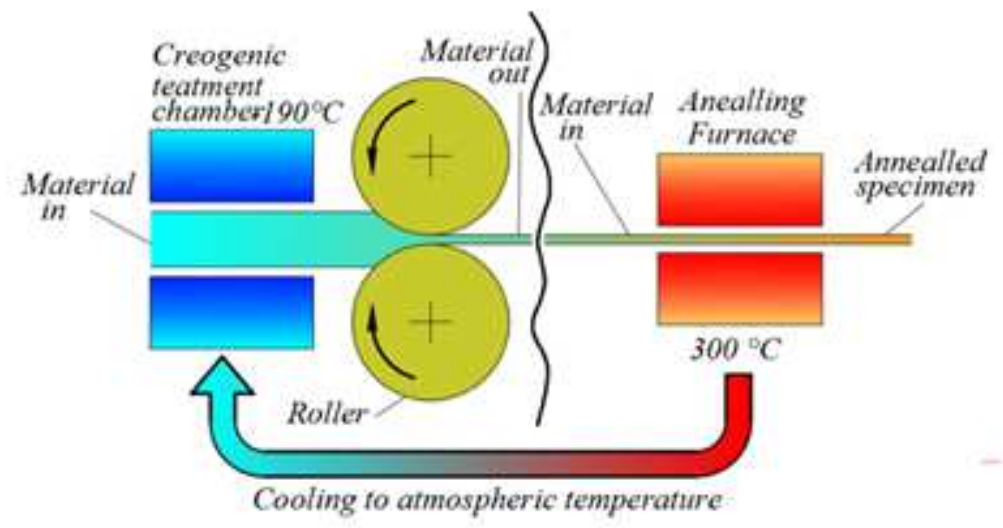

\section{Figure 1}

Schematic arrangement of rolling process
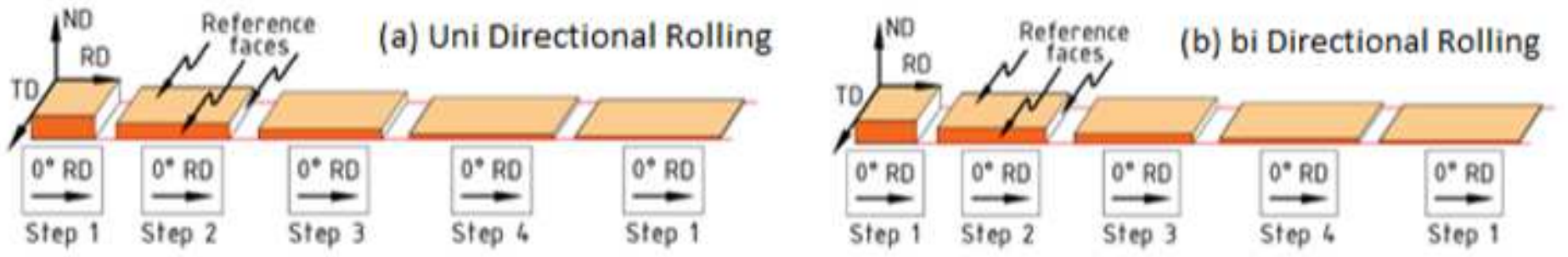

Figure 2

$(a, b)$ Process route sequence - Uni and bi directional rolling
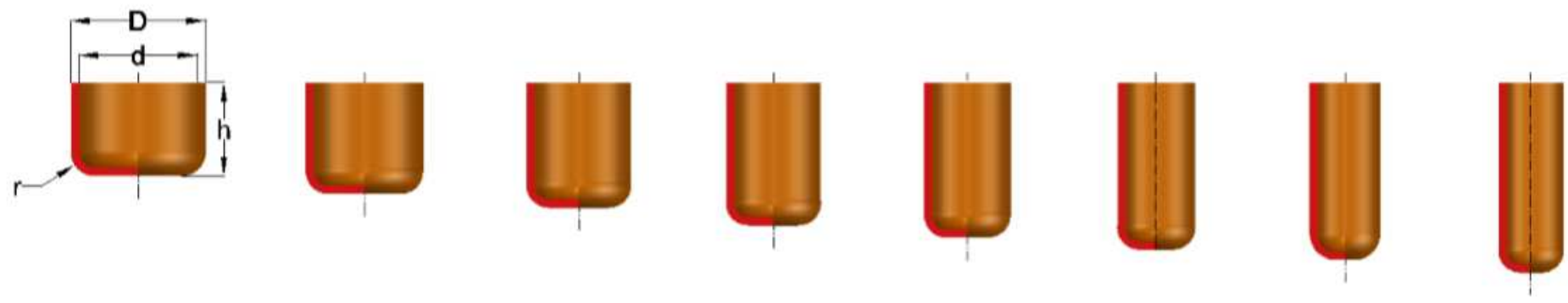

Figure 3

Cup multi-stage (8 stage) drawing $(\rrbracket=1.0)$ for sheet thickness $3.0 \mathrm{~mm}$ 


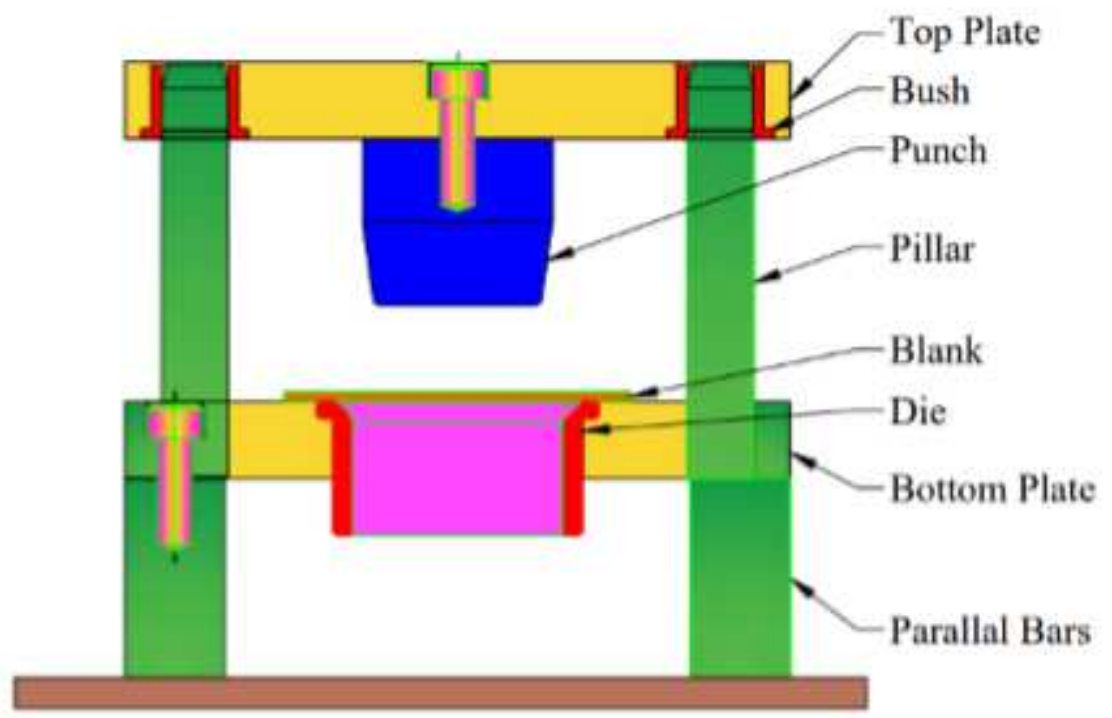

\section{Figure 4}

Schematic illustration press tool assembly operation

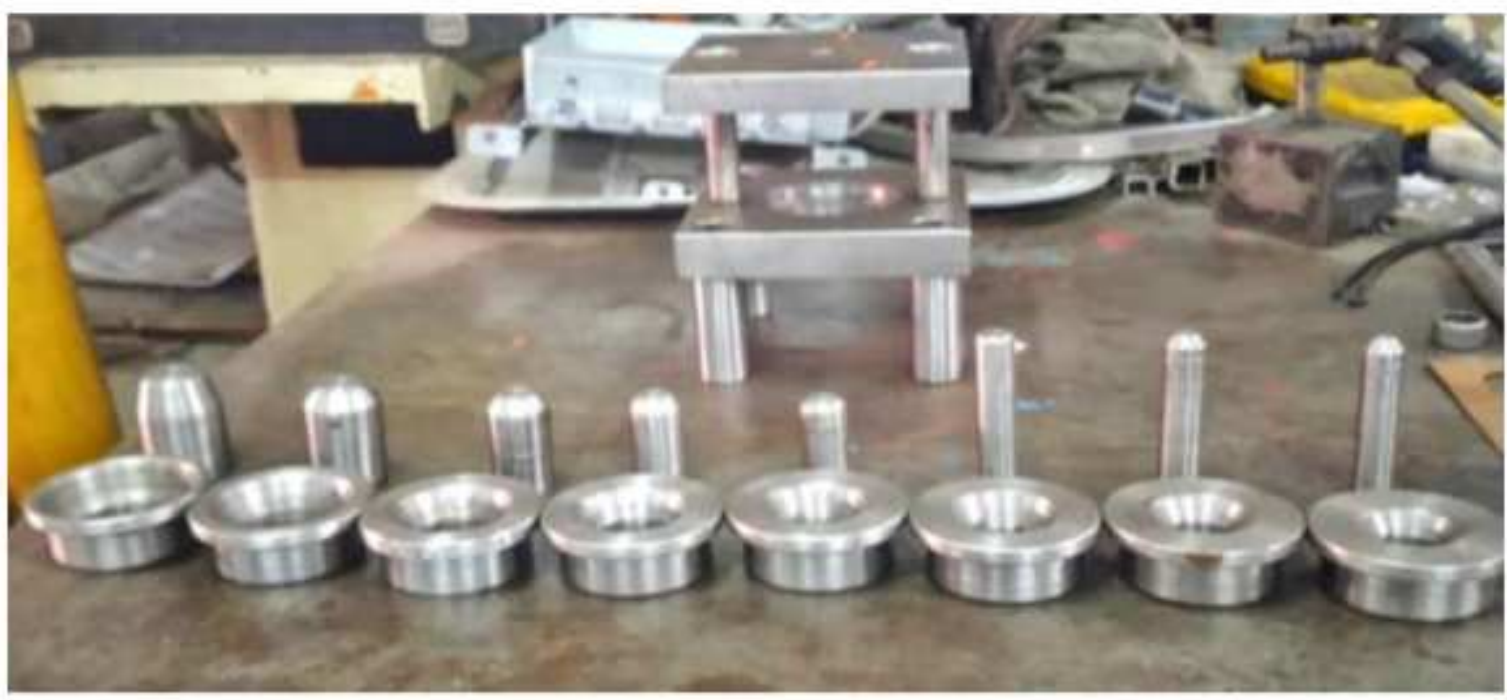

Figure 5

Illustration of the dies, showing different die sets, for drawing 


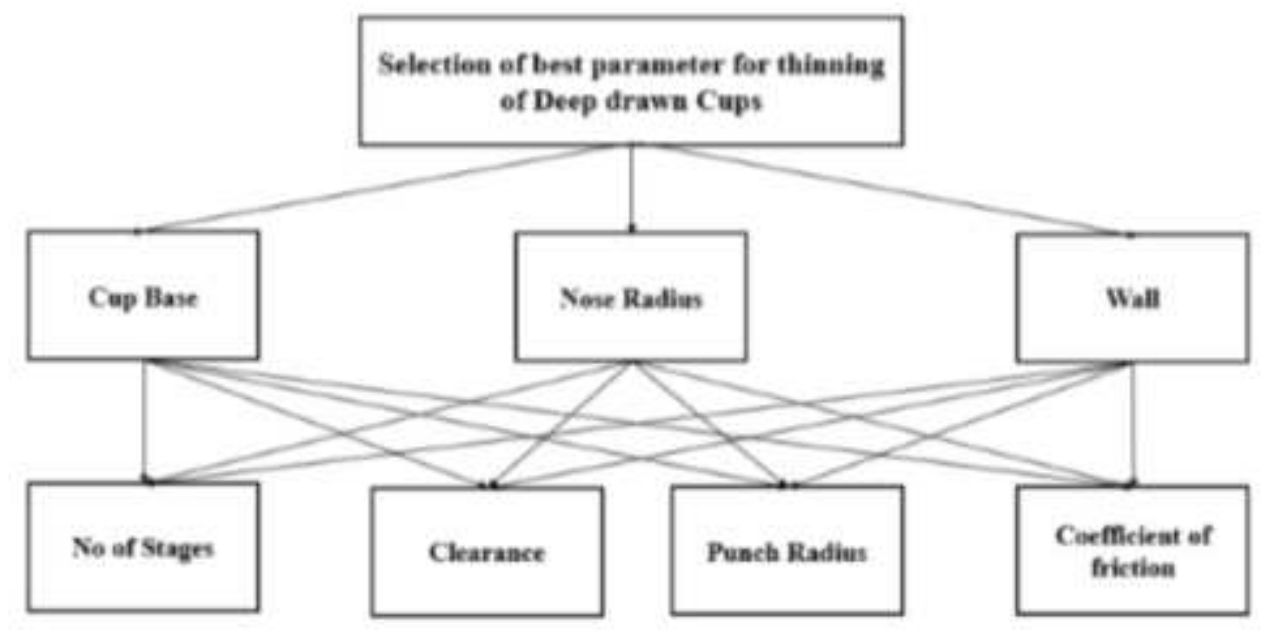

Figure 6

Hierarchy Structure of AHP

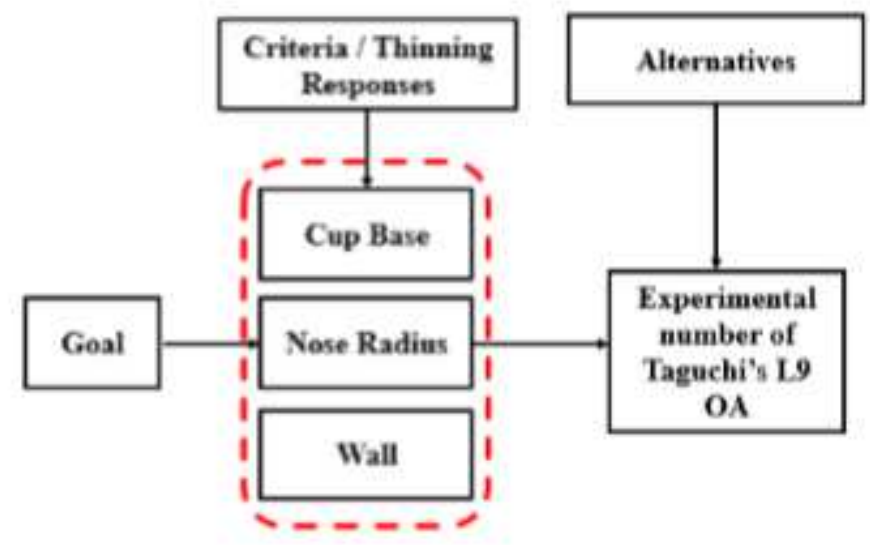

Figure 7

Hierarchy Structure of process parameters and Response 


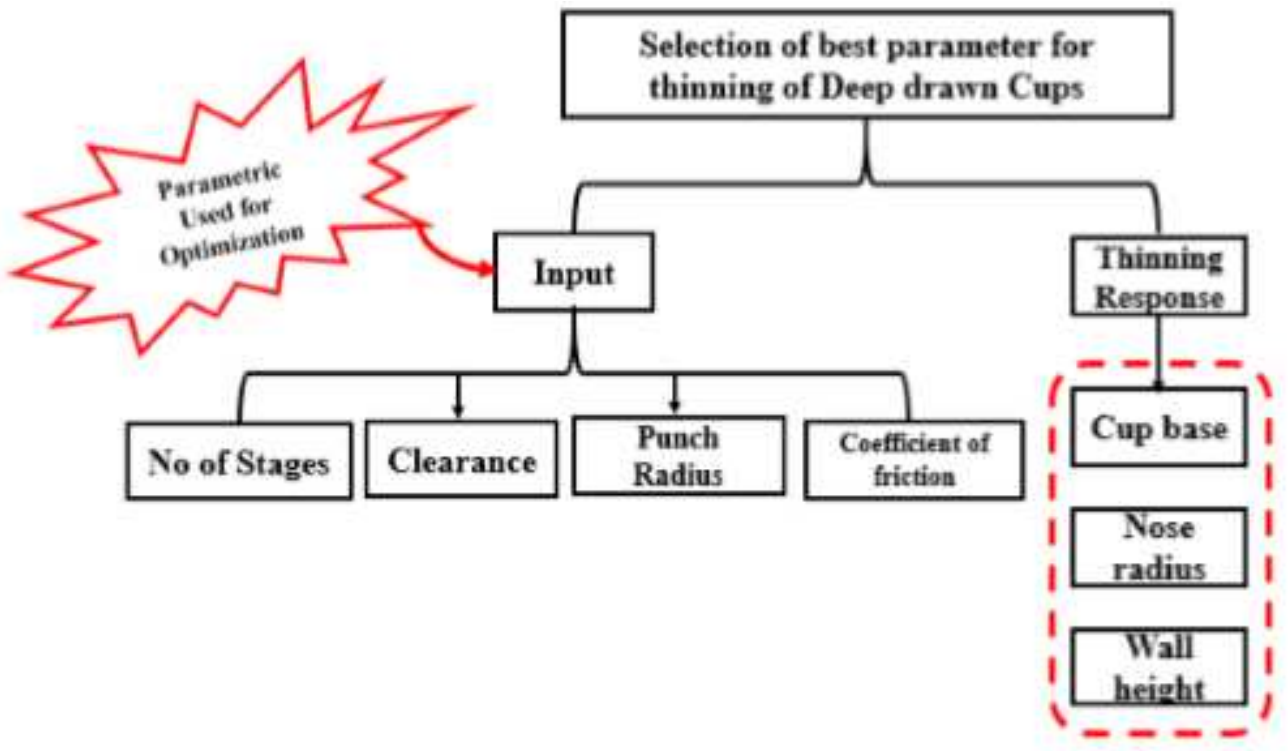

Figure 8

Process parameter and response
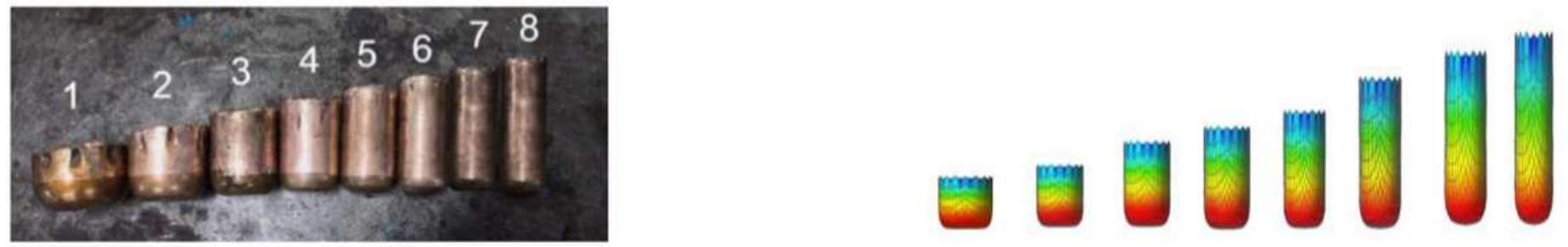

Figure 9

Optimizied Experimental and FEA Formed cups $(\mathbb{\nabla}=1)$

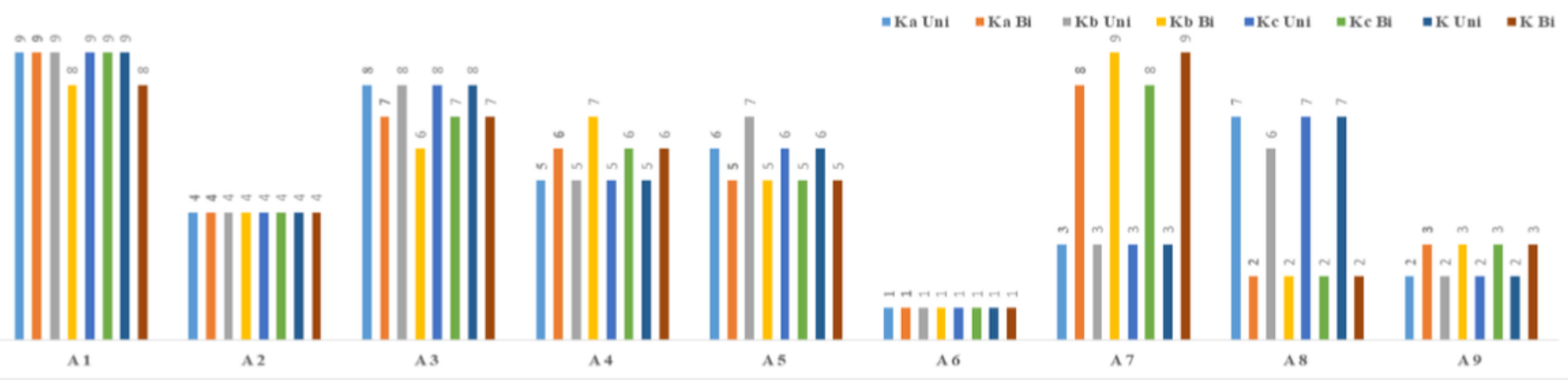

Figure 10

Comparison $\mathrm{k}$ values. 


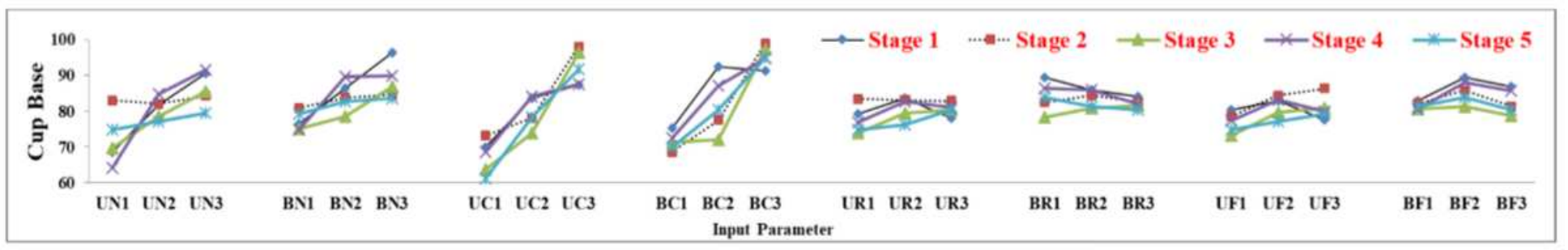

\section{Figure 11}

Effects on Cup base Uni and bi directional sample.

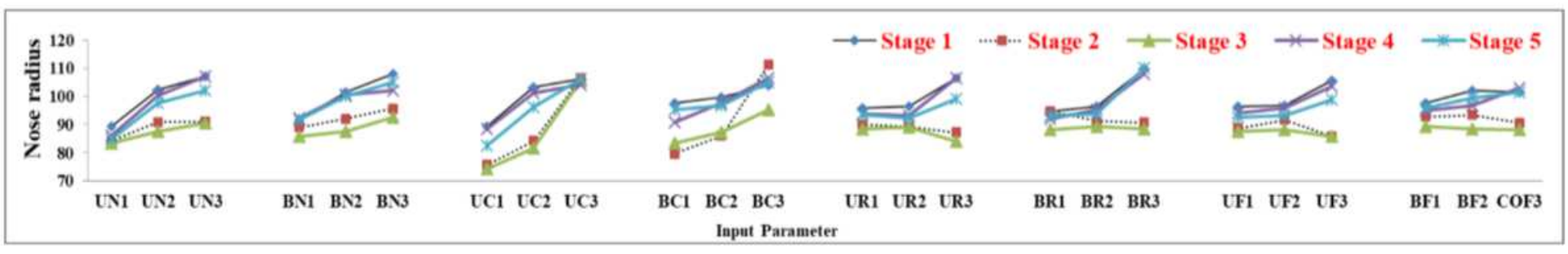

\section{Figure 12}

Effects on shoulder radius Uni and bi directional sample.

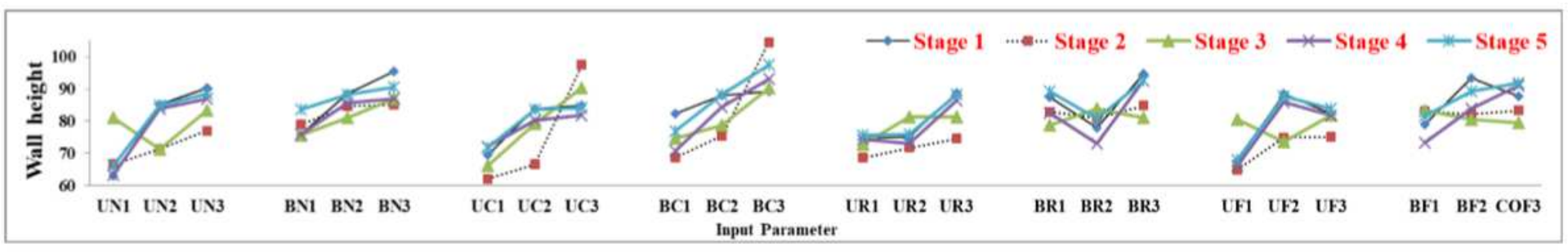

\section{Figure 13}

Effects on Wall height Uni and bi directional sample.

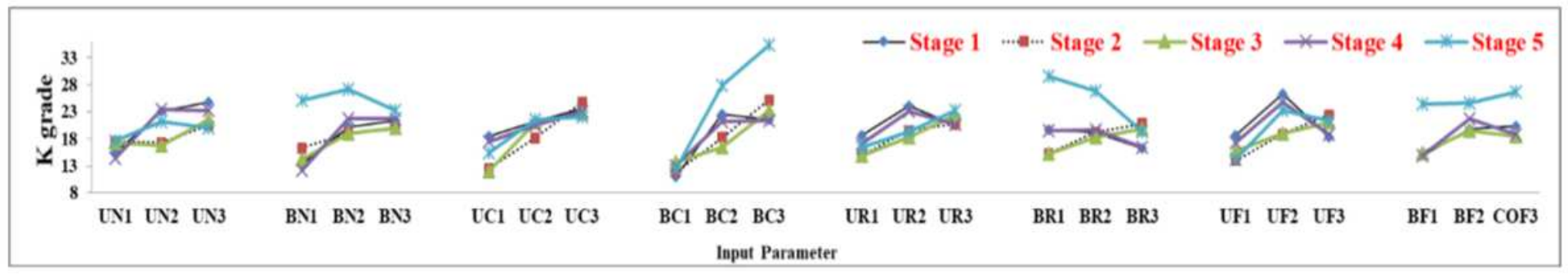

\section{Figure 14}

Effects on K Grades Uni directional and bi directional rolled sample. 

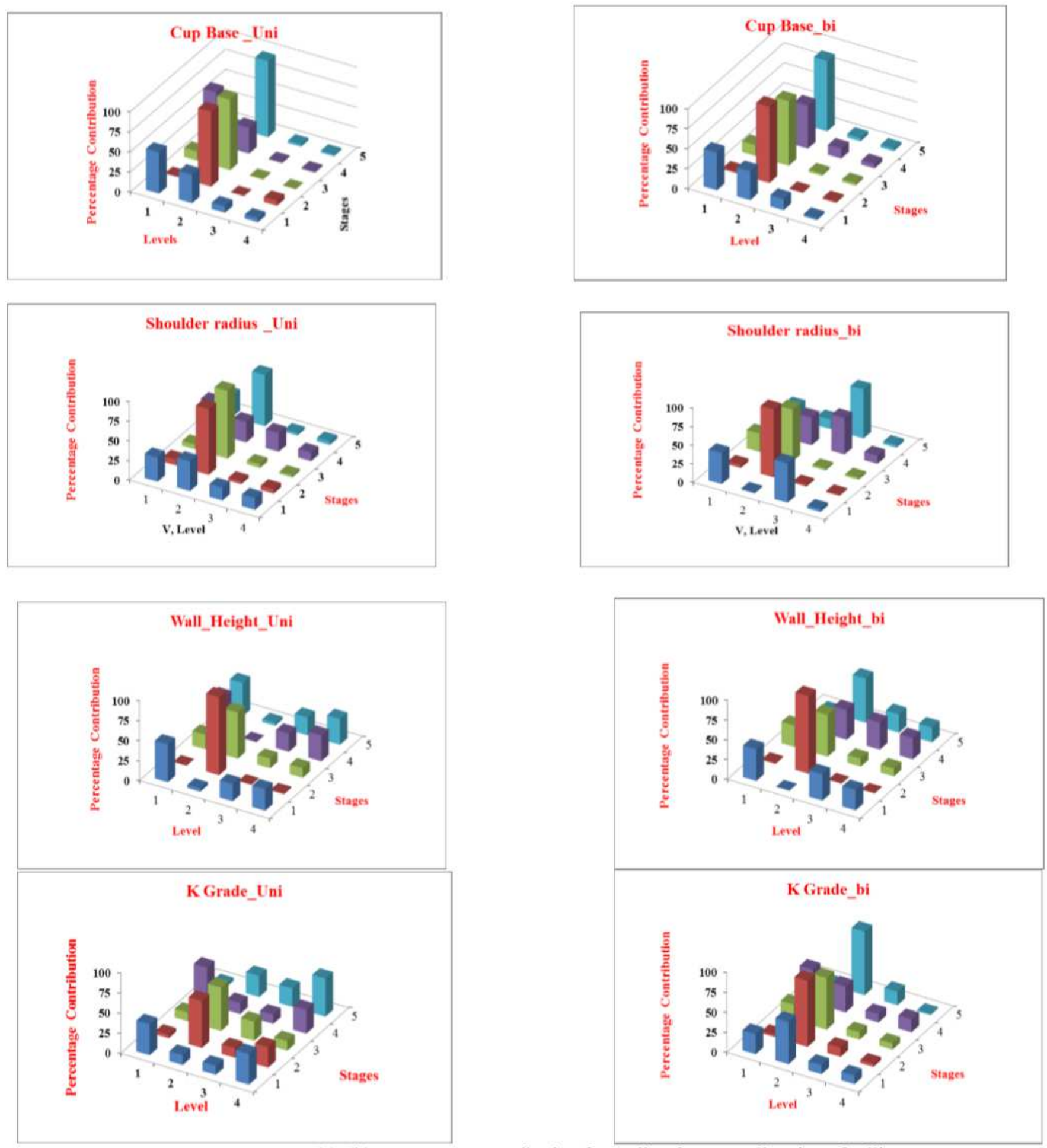

Figure 15

(a), (b), Percentage Contribution for scaling factor on direction of rolling 


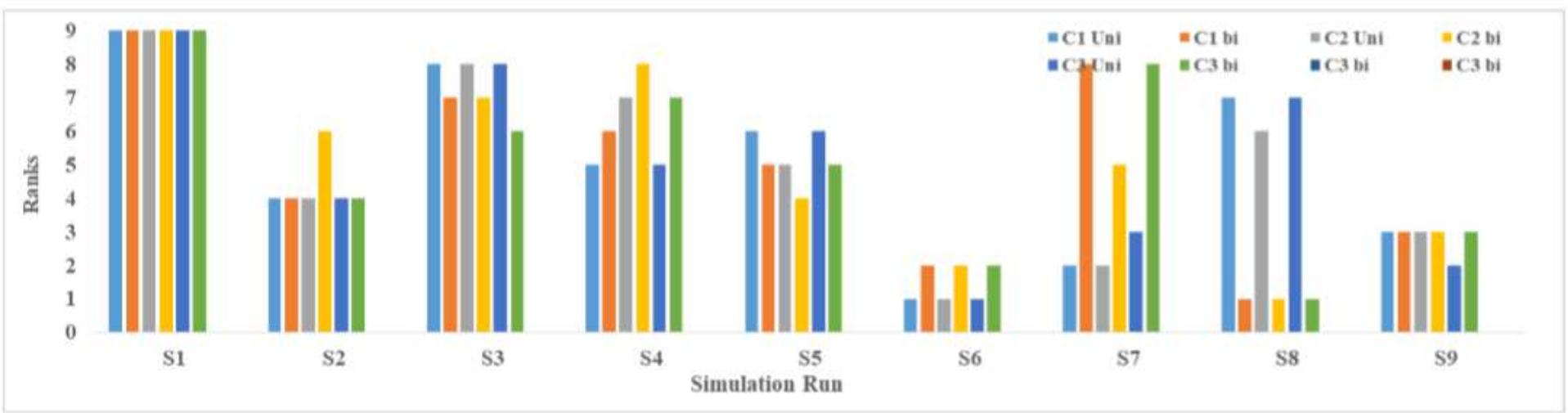

Figure 16

Sensitivity analysis 